\title{
Value- and ecosystem-based management approach: the Pacific herring fishery conflict
}

\author{
Mimi E. Lam ${ }^{1,2, *}$, Tony J. Pitcher ${ }^{2}$, Szymon Surma ${ }^{2}$, Jeffrey Scott $^{2}$, Matthias Kaiser $^{1}$, \\ April S. J. White ${ }^{3}$, Evgeny A. Pakhomov ${ }^{2,4,5}$, Lawrence M. Ward ${ }^{6}$ \\ ${ }^{1}$ University of Bergen, Centre for the Study of the Sciences and the Humanities, 5020 Bergen, Norway \\ ${ }^{2}$ University of British Columbia, Institute for the Oceans and Fisheries, Vancouver, Canada V6T 1Z4 \\ ${ }^{3}$ Wind Spirit Art, Old Massett, Haida Gwaii, Canada V8A 2 K8 \\ ${ }^{4}$ University of British Columbia, Department of Earth, Ocean and Atmospheric Sciences, Vancouver, Canada V6T $1 Z 4$ \\ ${ }^{5}$ Hakai Institute, Heriot Bay, Canada V0P 1 Ho \\ ${ }^{6}$ University of British Columbia, Department of Psychology, Vancouver, Canada V6T 1Z4
}

\begin{abstract}
An innovative value- and ecosystem-based management approach (VEBMA) is introduced that aims to expose policy tradeoffs, resolve resource conflicts, and foster ethical governance. VEBMA is applied to the Pacific herring Clupea pallasii fishery in British Columbia, Canada, which is mired in conflict between local and indigenous communities and the fishing industry over the management of herring, a forage fish with significant ecological, socioeconomic, and cultural value. VEBMA integrates an ecosystem-based approach (ecological modelling) with a valuebased approach (practical ethics) to examine the ecological viability, socioeconomic feasibility, and societal desirability of alternative fishery management scenarios. In the socioecosystem-based approach, we applied the Management Strategy Evaluation module within the Ecopath with Ecosim modelling framework to explore scenarios with harvest-control rules specified by various herring fishing mortalities and biomass cutoff thresholds. In the value-based approach, Haida Gwaii community and herring industry participants ranked a set of values and selected preferred scenarios and cutoff thresholds to open the fishery. The modelled ecological and socioeconomic impacts and risks and stakeholder preferences of the scenarios are synthesized in a deliberation and decision-support tool, the VEBMA science-policy table. VEBMA facilitates inclusive, transparent, and accountable decision-making among diverse stakeholders, such as local communities, industries, scientists, managers, and policy-makers. It promotes ethical governance in pluralistic societies via compromise, rather than consensus solutions to resolve 'wicked' problems at the science-policy interface.
\end{abstract}

KEY WORDS: Ecosystem-based management - Values · Policy tradeoffs · Ethical governance * Resource conflicts · Wicked problems - Science-policy interface · Decision-support tools · Management strategy evaluation $\cdot$ Lenfest recommendations $\cdot$ Forage fish

\section{INTRODUCTION}

\subsection{Fishery policy is 'wicked'}

Fishery policy problems are 'wicked' (Rittel \& Webber 1973, Jentoft \& Chuenpagdee 2009, Weber et al. 2017), characterized by a plurality of values that defy definitive descriptions or unique solutions. As a con-

${ }^{*}$ Corresponding author: mimi.lam@uib.no sequence, fishery conflicts (Charles 1992) often arise when diverse values, interests, and world-views clash over who owns or controls the fishery resources and how they should be managed and allocated. Fisheries science focuses on single-species or ecosystembased (albeit seldom implemented) approaches to management and the ecological and economic implications of fishery policy, and only seldom considers

() The authors 2019. Open Access under Creative Commons by Attribution Licence. Use, distribution and reproduction are unrestricted. Authors and original publication must be credited. 
this social context when recommending management strategies or policy options. However, value conflicts can prevent uptake of scientific advice at the science-policy interface, distorting policy outcomes. The political influence that stakeholder interests can exert on decision-making is evident in Japan's 'scientific whaling' (Clapham 2015) and in the European Union's total allowable catches, which, in the period 1987-2011, averaged $33 \%$ higher than the scientific recommendations (O'Leary et al. 2011). Making transparent the diverse (e.g. ecological, socioeconomic, and cultural) values and impacts associated with different fishery policies and management scenarios may foster dialogue among stakeholders and aid decision-makers in resolving policy tradeoffs and resource conflicts. Ultimately, recognizing the wicked nature of fishery policy problems can lead to more ethical governance (Lam \& Pauly 2010, Lam \& Pitcher 2012). Ethical governance is participatory, deliberative, transparent, and accountable decision-making designed to synthesize diverse sources of information and reconcile a plurality of values among stakeholders (Lam 2016a). It thus encompasses responsible (Sissenwine \& Mace 2003), ecosystem-based (Berkes 2012), and good (Lockwood et al. 2010) governance.

To tackle such wicked fishery policy problems, we developed a value- and ecosystem-based management approach (VEBMA), with trans-disciplinary research (Johnson et al. 2019) that merges theory and methods from ecology, oceanography, philosophy, psychology, and art. We applied the VEBMA methodology to the Pacific herring Clupea pallasii fishery in British Columbia, Canada, to bring out critical aspects of the conflict between the herring industry and local communities. VEBMA combines ecosystem modelling with participatory value-based research to inform policy decisions by making explicit both the plurality of values underlying the conflict and the ecological and societal consequences of alternative fishery management scenarios. Ecosystem modelling was performed to assess the ecological impacts and risks of alternative management scenarios, such as how to manage herring populations vis-à-vis their predators (including commercial fishes and charismatic megafauna) and planktonic prey. Participatory research was conducted to reveal the diverse values at stake, perspectives, and scenario preferences among members of the herring industry and a largely indigenous local community. VEBMA's integrated value- and ecosystem-based management approach to good governance culminates in a deliberation and decision-support tool that exposes policy tradeoffs. The resulting science-policy table allows policy- makers and civil society to transparently weigh the consequences of alternative management scenarios and to resolve resource conflicts.

\subsection{Ecosystem-based management of forage fish}

Forage fish, such as herring, sardines, and anchovies (Clupeiformes), exhibit complex ecological and population dynamics that complicate their fishery management and policies (Surma et al. 2018b, Siple et al. 2019). These small pelagic fish play a pivotal role within marine food webs, notably in temperate and upwelling ecosystems, as trophic nodes linking larger vertebrate consumers with smaller planktonic invertebrates (Smith et al. 2011, Pikitch et al. 2012, 2014, Engelhard et al. 2014, Surma et al. 2018a,b). Trophic interactions between forage fish and their predators, i.e. carnivorous fish, marine mammals, and seabirds (Engelhard et al. 2014, Essington \& Munch 2014) may be governed by bottom-up (Cury et al. 2011, Hannesson 2013, Sydeman et al. 2017) or top-down (Houle et al. 2013, Surma \& Pitcher 2015, Moran et al. 2018) control. Forage fish population dynamics are characterized by an $r$-selected life history strategy: i.e. high population growth rates, $r$, fecundities, and natural mortalities; early maturation; and asymptotic stockrecruitment curves that rise steeply near the origin (Adams 1980, King \& McFarlane 2003, Pikitch et al. 2014). Forage fish schooling behaviour leads to enhanced vulnerability to fishing, which promotes range collapses at low abundance (Pitcher 1995, 2001). Fishing and climatic drivers may exacerbate these issues to cause high-amplitude recruitment fluctuations (Pikitch et al. 2014, McClatchie et al. 2017), which in turn can lead to stock collapses (Hannesson 2013, Pinsky \& Byler 2015, Essington et al. 2015). The Lenfest Forage Fish Task Force has called for precautionary ecosystem-based fisheries management (EBFM) of forage fish (Pikitch et al. 2012, 2014), owing to their vulnerability to fishing and their importance to fished, charismatic, and protected predators; this, however, has not been without debate (Walters et al. 2016, Hilborn et al. 2017, Pikitch et al. 2018).

EBFM attempts to preserve the structure and function of the ecosystem or food web, i.e. the target fish species, their prey and predators, and protected species that encompass the entire resource system (Link 2002, 2010, Pikitch et al. 2004, Marasco et al. 2007, Patrick \& Link 2015). This is broader than the ecosystem approach to fisheries (EAF), which considers only the target species or resource and its drivers (Garcia et al. 2003, Garcia \& Cochrane 2005). By 
explicitly incorporating forage fish and their fisheries into entire food webs, ecosystem modelling can systematically compare the ecosystem impacts of alternative management scenarios (Walters et al. 2005, Pikitch et al. 2012), potential precautionary reference points (Smith et al. 2011, Pikitch et al. 2012, 2014), and EBFM approaches (Plagányi 2007, Engelhard et al. 2014, Essington \& Munch 2014). To protect the ecosystem-provisioning role of forage fish, it has been recommended (1) to leave at least one third of forage fish biomass for seabirds (Cury et al. 2011); (2) to reduce forage fish fishing mortality rates to $~ 50 \%$ of natural mortality rates, i.e. to $\sim 50 \%$ of conventional fishing mortality rates aimed at maximum sustainable yield (MSY; Smith et al. 2011, Pikitch et al. 2012); and (3) to increase minimum biomass cutoff thresholds for opening the commercial fisheries to $40 \%$ of the estimated unfished biomass, with recommendations tailored to the information available (Lenfest intermediate information tier; Pikitch et al. 2012, 2014).

Ecosystem-based management (EBM) of marine resources (Browman \& Stergiou 2004, 2005) considers the entire integrated ecosystem, including humans (McLeod \& Leslie 2009). While conceptually appealing (Grumbine 1994, Larkin 1996), both EBM and EBFM suffer from high system complexity, uncertainty, and competing interests and goals (Pikitch et al. 2004). This creates scientific and implementation challenges, both in policy and practice (Ruckelshaus et al. 2008). Managing multi-species interactions with multiple human agencies, objectives, and stakeholders has led to largely ineffective coordination and collaboration across diverse sectors, activities, and jurisdictions, with ecosystem-based (EB) considerations rarely quantitatively incorporated in setting harvest quotas (Pitcher \& Lam 2010). Evaluation of the status of EBFM implementation in the 33 top fishing nations yielded dismal results: no country scored 'good', only 4 were 'acceptable', and 18 had 'fail' grades (Pitcher et al. 2009). Reconciling EBFM policy tradeoffs (Link 2010, Siple et al. 2019), as in Antarctica (Constable 2011) and the Baltic Sea (Möllmann et al. 2014), requires ethical (Lam \& Pauly 2010, Lam \& Pitcher 2012) governance approaches that weigh diverse values.

\subsection{Adding value to ecosystem-based management approaches}

Balancing sustainable use and biodiversity conservation in fisheries management requires identifying socially acceptable ecological impacts and risks (Jen- nings et al. 2014). This becomes clear when one recognizes that '[m]anagement goals are statements of values - certain outcomes are selected over others' (Grumbine 1994, p. 32). Though values orient and motivate human activities (Brosch \& Sander 2016a), their explicit articulation in traditional approaches to resource management, including EBFM, is missing. Value-based (VB) approaches are needed to aid decision-makers in resolving policy tradeoffs and resource conflicts. Values are explicitly recognized in wicked problems (Rittel \& Webber 1973, Weber et al. 2017), post-normal science approaches to sciencepolicy problems (Funtowicz \& Ravetz 1990, 1993), structured decision-making for environmental management choices (Gregory et al. 2012), understanding environmental behaviours and decisions (Dietz 2016), communicating science (Dietz 2013), and the Intergovernmental Platform on Biodiversity and Ecosystem Services (IPBES) human-nature conceptual framework (Díaz et al. 2015, 2018). In structured decision-making, multi-criteria objective measures are evaluated by technical experts to assess the consequences of alternatives, among which stakeholders choose by making value tradeoffs (Gregory 2002, Failing et al. 2013). This approach, however, assumes a clear separation of facts and values, which is rarely the case. Alternatively, value taxonomies (Rabinowicz \& Rønnow-Rasmussen 2016), as articulated by the IPBES (Chan et al. 2016, 2018), can focus policy options and clarify the source of conflicts when different kinds of values obscure decision-making. Simply categorizing values, however, does not resolve policy tradeoffs or resource conflicts. VB approaches are needed that systematically identify the plurality of values in differentiated publics and analyze how such values interact to influence individual and policy decisions. An empirical science of values that not only recognizes their dynamic and context-specific nature, but also investigates how values alter the perception and uptake of 'facts' in decision-making processes may help to resolve resource conflicts.

Valuation approaches that research the process of attributing value to something (Brosch \& Sander 2016b, Pascual et al. 2017) may provide the often missing context to value-based decisions by relating values to decision-making and action. One emerging valuation framework maps decision values of different choice options in individual 'value landscapes', where different value landscapes reflect different weightings of core values (Brosch \& Sander 2016b). European 'value landscapes and isobars' were mapped to detect areas of convergence and conflict as blueprints to promote better dialogue for value-informed governance 
of science and technology (Kaiser 2012). Applying this practical ethics approach, Bremer et al. (2016) asked Asian stakeholders to rank values, to map value landscapes for aquaculture development scenarios, and to produce sustainability indicators. Values were also ranked in an interactive ' $\mathrm{P}+$ sort' method designed to elicit stakeholder values and principles to guide fishery governance in South Korea (Song \& Chuenpagdee 2015) and in a Q sort methodology designed to examine how people prioritize outcomes of marine management in Haida Gwaii, Canada (Loring \& Hinzman 2018). These VB studies, however, did not investigate the ecological impacts and risks of the management or governance scenarios. VB approaches offer a lowcost heuristic in data-poor or uncertain conditions, but need to be complemented with EB approaches to identify not only desirable, but also sustainable natural resource policy options.

Hence, we present an innovative value- and ecosystem-based management approach (VEBMA) that integrates $\mathrm{EB}$ and $\mathrm{VB}$ approaches to marine resource management. VEBMA's strengths and weaknesses are examined in the context of a case study, the Pacific herring fishery conflict in western Canada. We conclude with reflections on VEBMA's methodological innovation, its ecological, management, policy, and governance implications for the Pacific herring fishery, and its potential generalizability to resolving resource conflicts and to facilitating ethical governance capable of resolving resource conflicts.

\section{MATERIALS AND METHODS}

\subsection{The context: Pacific herring fishery conflict}

VEBMA was developed to help resolve the Pacific herring Clupea pallasii fishery conflict between coastal and indigenous communities and the herring industry in British Columbia (BC), Canada (Lam 2015, Levin et al. 2016, Pitcher et al. 2017). Pacific herring have ecological, socioeconomic, and cultural values that are often absent in evaluations of herring fishery policy options. To facilitate ethical governance, VEBMA makes explicit the diverse values, impacts, and risks of alternative herring fishery management scenarios to the marine food web, local herring industry, and coastal and indigenous communities.

National oceans legislation (Canada's Oceans Act 1997, DFO 2002) is guided by the principles of sustainable development, the precautionary approach, and integrated management. Despite this, the federal regulatory body responsible, Fisheries and Oceans
Canada (DFO), manages herring using a single-species rather than ecosystem-based approach (Baum \& Fuller 2016, DFO 2018, 2019). This management approach largely ignores the critical role of herring in the Northeast Pacific food web, i.e. its ecological value, as a forage fish (Shelton et al. 2014, Surma et al. 2018b) and major energy conduit (Surma et al. 2018a) between zooplankton prey (mainly euphausiids, amphipods, and copepods) and predators (carnivorous fish, marine mammals, and seabirds). Ecosystem simulation modelling suggests that herring depletion would adversely affect not only the commercial herring fishery, but also predator populations, with impacts cascading through the Northeast Pacific or Haida Gwaii marine food web (Surma et al. 2018b).

The BC herring fishery includes commercial roe herring (gillnet and seine), spawn-on-kelp (SOK), and food, bait and other, as well as a traditional food fishery. In the 1950s and 1960s, the BC industrial reduction fishery depleted herring stocks, leading to a province-wide closure from 1967 to 1971 (Pitcher et al. 2017). A lucrative roe herring fishery started in BC in the 1970s in response to the collapse of Hokkaido herring stocks, but declining Japanese export demand (Carlson 2005) has drastically reduced its socioeconomic value. In 2017, the roe herring fishery and its products, herring roe, herring meal, and animal feed, accounted for the largest share of the herring harvest $\left(73 \%, 20400 t_{i}\right.$ cf. over $500000 t$ at its peak in the $1960 \mathrm{~s})$, landed value (64\%, $\$ 17.7$ million USD), and wholesale value $(75 \%, \$ 51.2$ million USD). The (non-capture) SOK fishery had the second largest share of herring landed value $(24 \%)$, while the food, bait, and other had the second largest herring harvest $(26 \%)$ and wholesale value (15\%) (British Columbia Ministry of Agriculture 2019). Ownership of BC herring fishing licenses is highly concentrated, with one vertically integrated corporate entity (a dominant processor) controlling $21 \%$ of gillnet, and $26 \%$ of seine licenses, and harvesting $24 \%$ of the roe herring catch in 2012 (Haas et al. 2016).

Pacific herring also have significant cultural value for BC coastal indigenous communities, notably the Haida (Jones et al. 2017), Heiltsuk (Gauvreau et al. 2017), and Nuu-chah-nulth First Nations (Uu-a-thluk 2018), as well as the Tlingit in Southeast Alaska (Thornton 2015). Herring eggs or roe laid on organic substrates, such as kelp fronds (SOK) or Western hemlock Tsuga heterophylla branches, constitute traditional foods and trade goods (Thornton et al. 2010, Moss 2016). In Canada, First Nations have an Aboriginal right to fish for food, social, and ceremonial purposes, which takes priority, after conserva- 


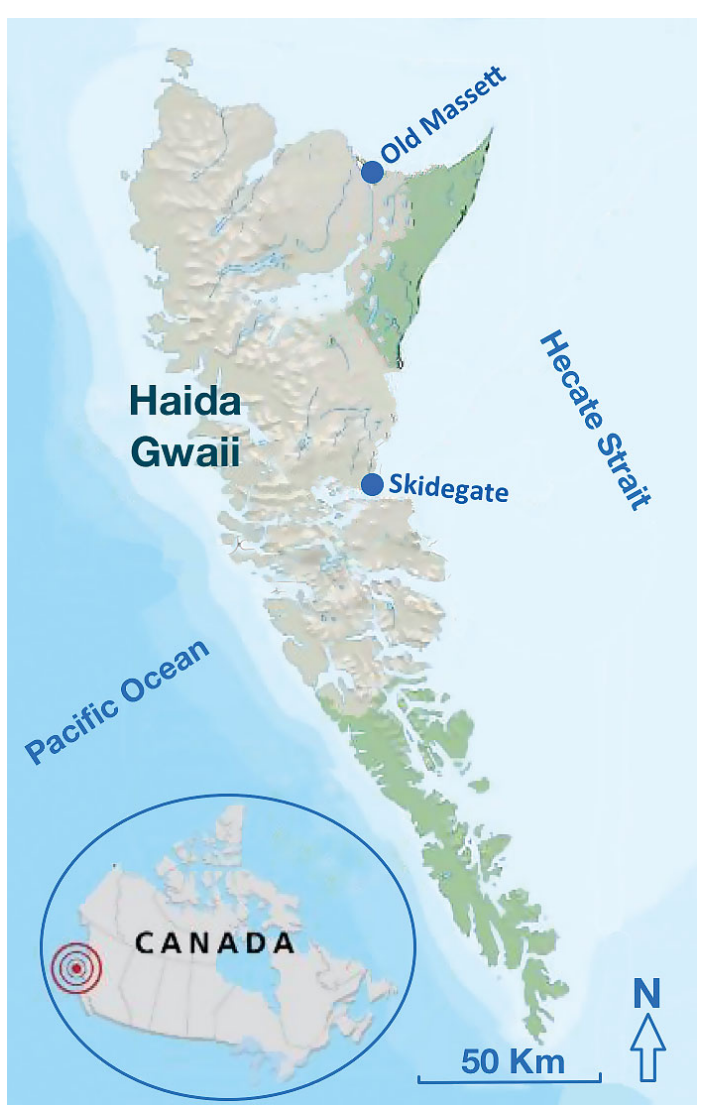

Fig. 1. Case study area: Haida Gwaii ('Islands of the People'), an archipelago in northern British Columbia, Canada, and ancestral homeland of the (indigenous) Haida, showing its surrounding waters, a highly productive and diverse marine ecosystem in the Northeast Pacific

tion, over other uses (Constitution Act, 1982; Canada. Department of Justice 2013). In the landmark Regina v. Gladstone case (Harris 2000), the Supreme Court of Canada recognized the Heiltsuk Nation's unextinguished Aboriginal right to a commercial SOK fishery. Amidst this legal context, BC First Nations are seeking to secure their fishing rights and protect their cultural and commercial interests in herring SOK (von der Porten et al. 2016).

In Haida Gwaii, an archipelago in northern BC and ancestral homeland of the Haida (Fig. 1), the commercial roe herring and SOK fisheries have been closed since 2003 and 2005, respectively (DFO 2016a). Despite poor stock status and uncertain forecasts, the Minister of Fisheries and Oceans re-opened the commercial herring fishery in both 2014 and 2015 (Lam 2015, von der Porten et al. 2016, Jones et al. 2017, Pitcher et al. 2017, Raman et al. 2018). Negotiations between the Council of the Haida Nation (CHN) and the industry averted serious conflict in 2014, while in 2015, the CHN won an interlocutory injunction to keep the fishery closed, with the Federal Court judge citing the potential for irreparable harm to herring and to Haida Aboriginal rights (Jones et al. 2017, Raman et al. 2018). Since 2016, under a new federal government, the commercial herring fishery has remained closed in Haida Gwaii.

\subsection{Novel methodology: value- and ecosystem- based management approach (VEBMA)}

VEBMA was conceptualized by M. E. Lam by synthesizing theory and methods from ecology merging theory and methods from ecology, oceanography, philosophy, psychology, and art. VEBMA combines EB and VB approaches to resource management to explicate the ecological and societal values underlying resource conflicts and the impacts and risks of policy tradeoffs. Ecosystem modelling, the EB component, explores interactions of herring populations vis-à-vis their prey and predators to assess the ecological impacts and risks of alternative management scenarios. Practical ethics, the VB component, reveals diverse stakeholder values, knowledge, and preferences. VEBMA's integrated approach is both descriptive and evaluative: it culminates in the VEBMA sciencepolicy table, a deliberation and decision-support tool that makes transparent the ecological and societal implications of alternative fishery policy choices. This prepares the ground for normative judgments in ethical decision-making and governance.

\subsubsection{Ecosystem-based (EB) approach: ecosystem modelling}

Ecopath with Ecosim (EwE) framework. VEBMA's EB component relies on ecosystem simulation modelling, specifically the Ecopath with Ecosim (EwE) framework (Christensen \& Walters 2004), to describe the ecological and socioeconomic impacts and risks of alternative fishery management scenarios. Ecopath creates, based on the principle of mass balance, a static food web model parameterized with ecophysiological parameters and diet data. This ecosystem 'snapshot' is used to calculate ecological metrics and serves as the initial state for dynamic simulations in Ecosim. Ecosystem dynamics can be driven by time series of primary production and are determined by a predator-prey foraging arena algorithm, where vulnerability parameters are fitted to empirical time series survey data, such as biomasses and catches. EwE is the most widely used modelling tool for eco- 
system approaches to fisheries management, as it can identify and quantify major energy flows in an ecosystem, describe the ecosystem resources and their interactions with each other and unfished species, evaluate ecosystem effects of fishing or environmental changes, and explore management policy options by incorporating ecological, economic, and social dimensions of fisheries (Plagányi 2007). Strengths of EwE are its structured parameterization framework, conceptual realism, and predator-prey interaction terms, while its weaknesses arise primarily from user misuse (Plagányi 2007). To address this issue and to better inform management, guidelines were identified for building and balancing Ecopath models, fitting Ecosim models to time series data, using EwE models, and evaluating output uncertainties (Heymans et al. 2016).

The EwE model of the Haida Gwaii marine food web and fisheries (details in Kumar et al. 2016) was updated from Ainsworth et al. (2008) and uses over $50 \mathrm{yr}$ of time series survey data from this location. Of the 56 functional groups in the EwE model, 4 are forage species: adult and juvenile Pacific herring, eulachon Thaleichthys pacificus, an aggregate of several smaller fish species (e.g. Pacific sandlance Ammodytes hexapterus, capelin Mallotus villosus, and small smelts), and krill (mainly Euphausia pacifica and Thysanoessa spp.). Since the diet of Pacific herring shifts with ontogeny (Beattie 1999, Pakhomov et al. 2017), a multi-stanza approach was used to represent herring by 2 age classes, namely, adults and juveniles, feeding predominantly on euphausiids and copepods, respectively, linked by a Beverton-Holt stock-recruitment relationship. Changes in functional group biomasses were simulated to investigate Northeast Pacific food web structure and function, as well as top-down (predators and fishing pressure) and bottom-up (primary production) forcing on Pacific herring (Surma et al. 2018b). The importance of herring to the food web was investigated by calculating the Supportive Role to Fishery ecosystems (SURF) index (Plagányi \& Essington 2014).

EwE Management Strategy Evaluation (MSE) or closed-loop simulations. As an innovation, to account rigorously for uncertainties in the policy context of the dynamic ecosystem simulation modelling, T. J. Pitcher determined to use EwE Management Strategy Evaluations (MSEs), rather than simple fishing choices, to compare the ecosystem outcomes of alternative herring fishery scenarios. MSE evaluates the performance of management scenarios (Fulton et al. 2014, Punt et al. 2016) against quantitative metrics relative to target fish stocks and food webs to com- pare the risks of policy choices (Kell et al. 2016). To account for uncertainty in primary production, each EwE MSE scenario was run for 100 simulated years, with annual phytoplankton biomass driven by a single time series generated by Monte Carlo resampling (Surma \& Pitcher 2015) of observed values from 1950 to 2000 (Ainsworth et al. 2008). To replicate BC herring fishery management, annual quotas were set from herring biomasses determined by simulated stock assessments in the MSE module. Stochastic herring stock assessment error was simulated by 100 runs of each EwE MSE scenario, with Monte Carlo resampling of herring biomass estimates from assumed normal distributions (the coefficient of variation was 0.3 for adult herring and 0 for all other groups). Simulated food web effects from stock assessment uncertainty, however, are small relative to primary production uncertainty.

Impacts of the herring fishery management scenarios on herring and the marine food web were investigated for 2 types of harvest-control rules (HCRs): (1) constant target fishing mortality rate, $F$, and (2) step, with constant $F$ and a biomass cutoff threshold, $B_{\mathrm{c},}$ below which the herring commercial fishery is closed. $B_{\mathrm{c}}$ is expressed relative to the unfished spawning biomass, $B_{0}$. In the EwE simulations, $B_{0}$ is estimated from projected herring recovery under an Ecosim scenario of no herring fishing $(F=0)$ run for $1000 \mathrm{yr}$, whereas DFO estimates $B_{0}$ from historical abundances calculated by single-species stock assessment models that do not explicitly account for food-web interactions between herring and its predators and prey (Surma et al. 2017).

Table 1 lists the herring fishery management scenarios modelled within the EB approach using the EwE MSE module (Surma et al. 2018b), namely No FISHING ( $F=0$, i.e. no commercial herring fishery); SOK $(F=0.01$, the estimated maximum incidental herring mortality in the commercial SOK fishery); LENFEST PRECAUT ( $F=0.2, B_{\mathrm{c}} / B_{0}=70 \%$, using an earlier version of the model, but see Surma [2019], and informed by the Lenfest precautionary threshold of $80 \%$ for low information, Pikitch et al. [2012, 2014]); LENFEST ( $F=0.2, B_{\mathrm{c}} / B_{0}=40 \%$, informed by the Lenfest recommended threshold of $40 \%$ for intermediate information, Pikitch et al. 2012, 2014); $B C$ $\left(F=0.2, B_{\mathrm{c}} / B_{0}=25 \%\right.$, i.e. DFO policy $\left.{ }^{\mathbf{1}}\right)$; $\operatorname{OPEN}(F=0.2$,

\footnotetext{
${ }^{1}$ Here, we focus on the DFO policy of $F=0.2$ and $B_{\mathrm{c}} / B_{0}=$ $25 \%$ at the time of the study. DFO also has a precautionary policy of $F=0.1$, when herring biomass is near the cutoff or there are stakeholder concerns about stock status (see Surma et al. 2018b). After this research was completed, DFO set $B_{\mathrm{c}} / B_{0}=30 \%$ (Kronlund et al. 2018)
} 
Table 1. Herring fishery management scenarios in the VEBMA study: quantitative ecosystem-based (EB) scenarios, modelled using the EwE Management Strategy Evaluation (MSE) module, specified with their constant fishing mortality $F$ and step (constant $F$ with biomass cutoff thresholds $B_{\mathrm{C}} / B_{0}$ ) harvest-control rules (HCRs) and MSE labels, and their rough equivalence with the qualitative value-based (VB) scenarios, with their names and focal values

\begin{tabular}{|c|c|c|c|c|c|}
\hline Scenario description & $\begin{array}{c}\text { Fishing } \\
\text { mortality, } F\end{array}$ & $\begin{array}{l}\text { Biomass cutoff } \\
\text { threshold, } B_{\mathrm{c}} / B_{0}(\%)\end{array}$ & MSE label & Name & Focal Value \\
\hline No commercial herring fishery (Baseline) & 0 & $\begin{array}{c}\text { All (Roe, SOK, } \\
\text { Food, Bait \& Other): } 100\end{array}$ & NO FISHING & $\begin{array}{l}\text { A whale of } \\
\text { a time }\end{array}$ & Ecological \\
\hline Only commercial spawn-on-kelp (SOK) fishery & 0.01 & $\begin{array}{l}\text { Roe: } 100 \\
\text { SOK: } 0\end{array}$ & SOK & $\begin{array}{l}\text { The fish that } \\
\text { get away }\end{array}$ & Cultural \\
\hline No commercial herring fishery (Closure) & 0.2 & Roe \& SOK: 100 & & & \\
\hline $\begin{array}{l}\text { Lenfest precautionary (near Lenfest } B_{\mathrm{c}} / B_{0}=80 \% \\
\text { for low information) }\end{array}$ & 0.2 & $\begin{array}{l}\text { Roe \& SOK: } 75(\mathrm{VB}) \\
\text { and } 70(\mathrm{~EB})\end{array}$ & $\begin{array}{l}\text { LENFEST } \\
\text { PRECAUT }\end{array}$ & & \\
\hline $\begin{array}{l}\text { Lenfest recommended (near Lenfest } B_{\mathrm{c}} / B_{0}=40 \% \\
\text { for intermediate information) }\end{array}$ & 0.2 & $\begin{array}{l}\text { Roe \& SOK: } 50(\mathrm{VB}) \\
\text { and } 40(\mathrm{~EB})\end{array}$ & LENFEST & & \\
\hline DFO policy in British Columbia $(\mathrm{BC})^{\mathrm{b}}$ & 0.2 & Roe \& SOK: 25 & $B C$ & Hard of herring & Socioeconomic \\
\hline$B C$ scenario with no good primary production years & 0.2 & Roe \& SOK: 25 & $B C_{0.75}$ & & \\
\hline$B C$ scenario with only bad primary production years & 0.2 & Roe \& SOK: 25 & $B C_{0.25}$ & & \\
\hline Commercial herring fishery always open & 0.2 & Roe \& SOK: 0 & OPEN & & \\
\hline $\begin{array}{l}\text { Commercial roe herring and SOK fisheries } \\
\text { managed separately, with distinct HCRs }\end{array}$ & Unspecified & Unspecified & & $\begin{array}{l}\text { The little fish } \\
\text { that could }\end{array}$ & Plural \\
\hline $\begin{array}{l}\text { Commercial herring fishery managed for } \\
\text { maximum sustainable yield (MSY) }\end{array}$ & 0.4 & Roe \& SOK: 25 & $M S Y$ & & \\
\hline
\end{tabular}

$B_{\mathrm{c}} / B_{0}=0 \%$, i.e. fishery always open); and (singlespecies) $M S Y\left(F=0.4\right.$, i.e. estimated $F_{\mathrm{MSY}}$ using EwE, $B_{\mathrm{C}} / B_{0}=25 \%$ ). Table 1 also lists the corresponding qualitative scenarios investigated within the VB approach, described in Section 2.2.2.

Each EwE MSE scenario yielded probability distributions of functional group biomasses and herring catches across the 100 simulation years and 100 runs. Fishery impacts were assessed from the means (i.e. grand means over 100 simulation years of 100 runs) of the biomasses and catch distributions over the entire range (all quartiles) of stochastic inter-annual phytoplankton biomass variability (and herring stock assessment errors). Ecological risks of poor functional group biomasses from climate variability (and herring stock assessment errors) used the lowest quartile biomass changes as proxies. For the $B C$ scenario, ecological risks of potential climate shifts were examined by resampling phytoplankton biomasses from only below the third quartile of the historical distribution $\left(B C_{0.75}\right.$, representing 'no good primary production years') and from only below the lowest quartile $\left(B C_{0.25}\right.$, representing 'only bad primary production years'). Socioeconomic risks of the scenarios were assessed using simulated commercial herring catches (calculated from herring biomasses) as proxies for profit and probabilities of fishery closure (when her- ring biomass is below the cutoff threshold) as proxies for stability.

\subsubsection{Value-based (VB) approach: practical ethics}

Participatory approach. Ecosystem modelling can simulate the ecological impacts and risks of the investigated management scenarios, with their associated uncertainties, but cannot determine which scenarios are most desirable. To tackle such normative policy questions, M. E. Lam and M. Kaiser developed a VB approach incorporating citizen participation (Arnstein 1969) and practical ethics (Kaiser 2006, 2016, Lam 2016b). The VB approach was adapted from an ethical decision-support and participatory governance framework (Kaiser et al. 2007) designed to elicit both 'bottom-up' stakeholder and 'top-down' government and expert inputs (Bremer et al. 2016). Given the political context of the fishery conflict, we initiated our study with the Haida Gwaii community and herring industry outside of Haida Gwaii separately, with research participants identified in consultation with the CHN and the Herring Industry Advisory Board (HIAB), respectively. We used snowball sampling, a non-probability sampling technique, where participants suggested additional participants 
from among their contacts. Our sample is thus not representative, but rather, indicative of the diverse perspectives among members of the Haida Gwaii community and herring industry.

In April 2015, we held consecutive one-day workshops in Skidegate and Old Massett, Haida Gwaii $\left(\mathrm{n}_{\text {Skidegate }}=17 ; \mathrm{n}_{\text {Old Massett }}=9\right)$, introducing our research project and personnel (Lam 2015, PWIAS 2016, Pitcher et al. 2017). Between September 2015 and March 2016, M. E. Lam conducted in-depth, semistructured interviews of a cross-section of Haida Gwaii residents: Haida elders, leadership, and youth; commercial fishers and license owners; scientists; resource managers; conservationists; ecotourism operators; educators; journalists; and artists. The 47 Haida Gwaii interviewees $\left(\mathrm{n}_{\mathrm{HG}}\right)$ comprised 30 Haida, 16 non-Haida (1 unspecified); 37 men, 10 women, aged 21 to 91 ; and 15 commercial fishers, 13 with herring experience (all retired). We presented our results to community participants in April 2016.

In September 2016 M. E. Lam and J. Scott met with 5 HIAB members to engage herring industry participants. From October 2016 to May 2017, J. Scott interviewed 28 herring industry members $\left(\mathrm{n}_{\mathrm{HI}}\right)$ residing outside of Haida Gwaii, mostly in the Lower Mainland surrounding the Vancouver metropolitan area (Scott 2017): 23 fishers (22 roe herring: 13 gillnet, 9 seine; 1 SOK; 19 active; 4 retired) and 5 processors. All industry respondents were male, aged 28 to 78 , with 3 indigenous, 23 non-indigenous, and 2 declined to specify. In May 2017, the synthesized VEBMA results were vetted at a HIAB meeting, the multistakeholder Integrated Herring Harvest Planning Committee meeting chaired by DFO, and a final herring project meeting of representatives of the Haida and Heiltsuk First Nations and an interdisciplinary scientific team. While focus groups were interviewed separately, our results were discussed with them first separately, and then together.

In both the workshops and interviews, participants prioritized, i.e. ranked and discussed 12 values in a value prioritization or value-ranking exercise designed to map their value landscapes in relation to herring fishery management. Next, they were given background information via PowerPoint presentations on 4 topics: (1) Haida concerns about the herring fishery; (2) the main Lenfest findings; (3) the results of the ecological modelling; and (4) descriptions of 4 herring fishery management scenarios, including their ecological, socioeconomic, and cultural implications. They were then asked to indicate their management scenario and cutoff threshold preferences. Finally, in response to open-ended questions, participants shared their herring-related knowledge and experiences, perspectives on herring management, and reflections on what herring means to them.

As part of our participatory approach, we used images and descriptive scenario names to engage research participants and disseminate our results in public science communication activities (Vogl 2017, Murphy 2019). A. S. J. White, a Haida artist and geologist, associated images from her inventory that were resonant for her with the values and scenarios, explaining her rationale in the original workshops in Haida Gwaii. In the interviews, the artwork was incorporated without explanation in the value-ranking and scenario preference exercises, but we asked participants how the artwork may have influenced them. Similarly, rather than labelling the scenarios with nondescript numbers or letters, M. E. Lam and T. J. Pitcher created names to engage and elicit responses from the participants. We reflect on the potential impact on the results of the images and scenario names in our methodology in the 'Discussion'.

A defining aspect of our participatory VB approach is that we do not use a common value metric, as is done in economics (e.g. price, opportunity cost, or willingness to pay), but rather, we explicate the plurality of values that accompanies differentiated publics in wicked policy (Rittel \& Webber 1973) and post-normal science (Funtowicz \& Ravetz 1990, 1993) problems. Specifically, our methodology captures individual value-rankings and scenario preferences, which we analyze by examining their median group ranks and distributions, respectively, to suggest how to weight policy choices for society, given heterogeneous individual choices. Thus, our VEBMA methodology recommends compromise, not consensus policy solutions within pluralistic societies and offers an integrated value- and ecosystem-based approach to reconcile tradeoffs and resource conflicts among heterogenous objectives, value priorities, and policy preferences. While stakeholder preferences give a sense of the desirability of policy options, the simulated ecological and socioeconomic impacts and risks give information about their viability and feasibility, respectively. By synthesizing this information in the VEBMA science-policy table, overall sustainability and ethical governance (inclusive, transparent, and accountable decision-making) can be facilitated, while building trust and capacity among diverse stakeholders, including local communities, industry, scientists, managers, and policy-makers.

Value-ranking exercise: mapping value landscapes. The value-ranking exercise consisted of ranking a set of 12 culturally contextualized values: Respect, Bal- 


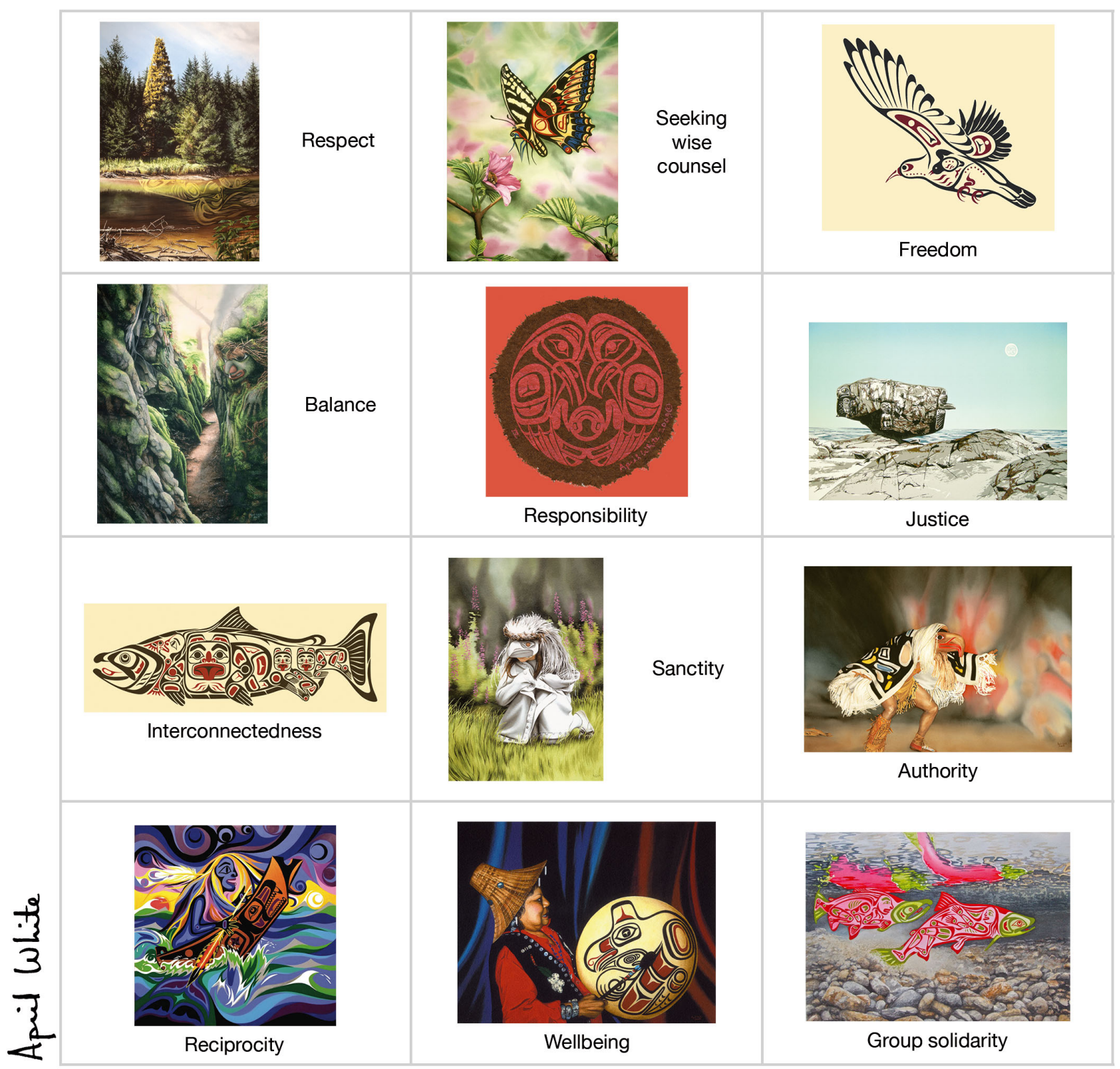

Fig. 2. Set of twelve $4^{\prime} \times 6^{\prime}$ value cards, with images by Haida artist and geologist April SGaana Jaad White, used in the valueranking exercise (value names have been shortened for visual clarity): Respect; Balance; Interconnectedness; Reciprocity; Seeking wise counsel; Responsibility; Sanctity; Wellbeing; Freedom; Justice; Authority; and Group solidarity. Table 2 lists the full names on the front and the text descriptions on the back of the value cards. All Fig. 2 images @April SGaana Jaad White

(no commercial herring fishery); (2) The fish that get away (only commercial SOK fishery); (3) Hard of herring (DFO policy); and (4) The little fish that could (commercial roe herring and SOK fisheries managed separately, with distinct HCRs). These 4 qualitative or narrative scenarios were designed after consultation with the CHN (but unfortunately, not with the HIAB, as the herring industry was engaged later) to highlight particular values of herring: ecological, cultural, socioeconomic, and plural, respectively (see Table 1). Respondents were asked also to select among 5 biomass cutoff thresholds for opening the commercial herring fishery: $B_{\mathrm{c}} / B_{0}=100 \%$ (fishery closed), $75 \%$ and $50 \%$ (approximate Lenfest recommendations for low and intermediate information, respectively), $25 \%$ (DFO policy), and $0 \%$ (fishery always open).

\section{RESULTS}

\subsection{EB approach: ecosystem modelling}

Fig. 4 depicts the EwE model of the Haida Gwaii marine food web and fisheries, with 56 functional 

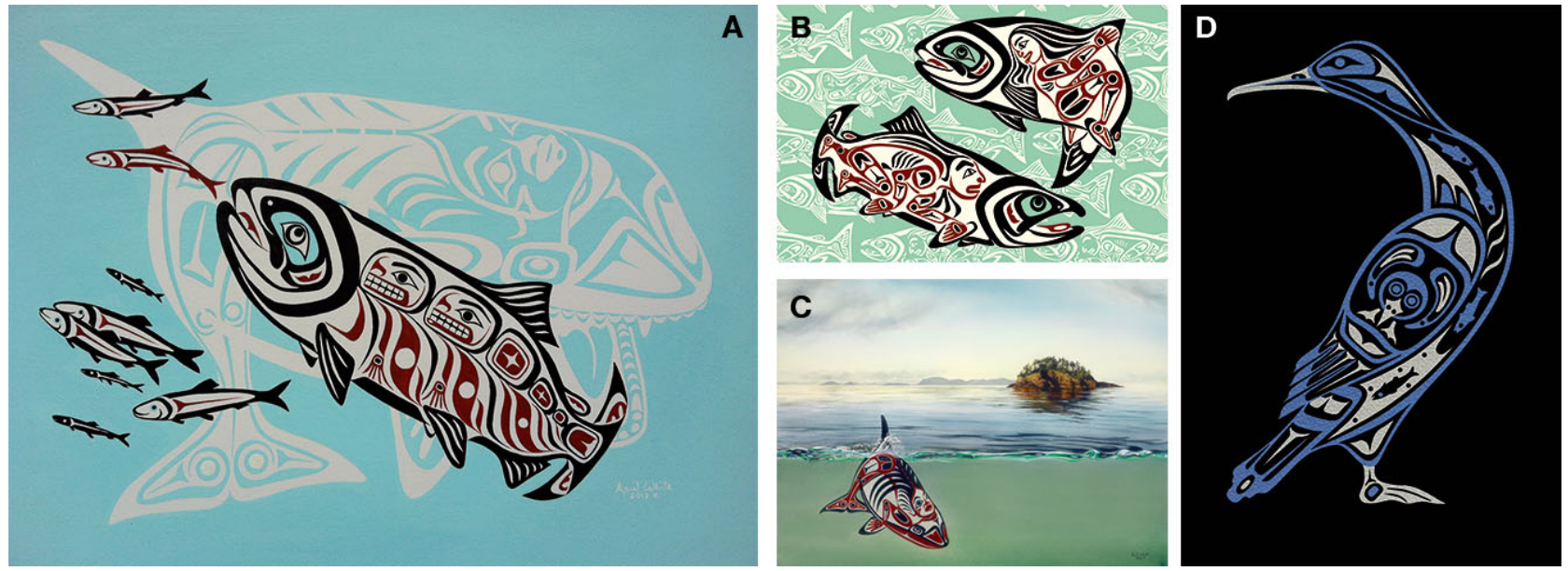

Fig. 3. Images used in the herring fishery management scenario preference exercise (see Table 1 for full scenario descriptions). (A) A whale of a time (no commercial herring fishery); (B) The fish that get away (only commercial spawn-on-kelp [SOK] fishery); (C) Hard of herring (DFO policy); and (D) The little fish that could (commercial roe herring and SOK fisheries managed separately, with distinct harvest-control rules). All Fig. 3 images @April SGaana Jaad White

groups spanning 5 trophic levels, from phytoplankton to orcas, and 21 commercial, recreational, and aboriginal fisheries, including roe herring (both seine and gillnet gear types), SOK, and food and bait. In our
Ecopath food web model, the SURF index was 0.0006 for herring, slightly below the threshold (0.001) for key forage fish status. However, the biomasses of $15 \%$ of non-herring groups decreased by $>60 \%$ in re-

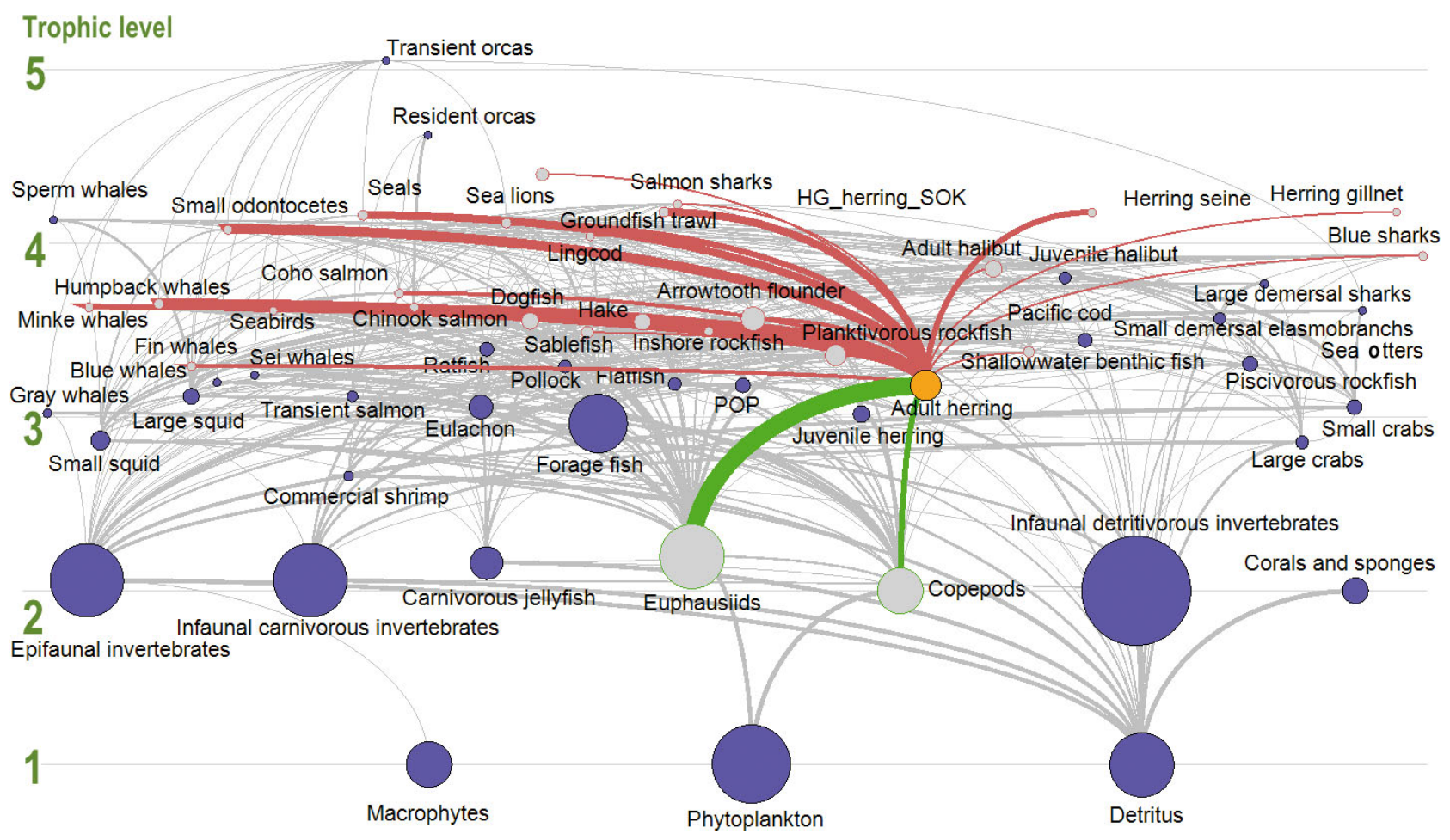

Fig. 4. Haida Gwaii marine food web and fisheries modelled using Ecopath with Ecosim (EwE), with 56 functional groups spanning 5 trophic levels, highlighting adult herring (orange dot) and biomass flows linking them with their prey (green lines) and predators (red lines). Line thickness is proportional to biomass flux ( $\mathrm{t} \mathrm{km}^{-2} \mathrm{yr}^{-1}$ ). EwE modelling results of the Haida Gwaii (i.e. Northeast Pacific) food web detailed in Kumar et al. (2016) and Surma et al. (2018b). Small odontocetes = dolphins and porpoises; POP = Pacific ocean perch; HG = Haida Gwaii; SOK = spawn-on-kelp 


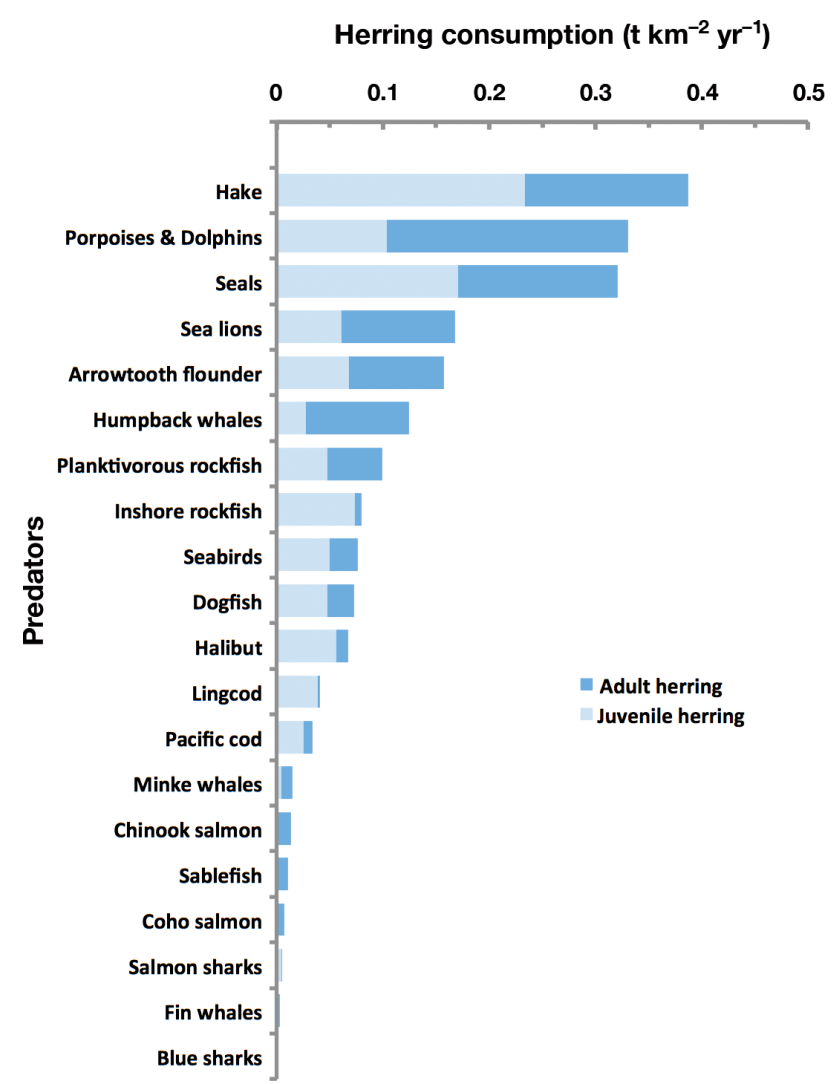

Fig. 5. Consumption of adult and juvenile Pacific herring by its 20 predators in the Haida Gwaii marine food web model

sponse to simulated herring depletion (Surma et al. 2018b), satisfying an alternate requirement for key status (Smith et al. 2011, Plagányi \& Essington 2014).

The total consumption of adult and juvenile herring by its 20 predators in the EwE model is approximately $2.0 \mathrm{t} \mathrm{km}^{-2} \mathrm{yr}^{-1}$ (Fig. 5). The flux of herring through the Haida Gwaii marine ecosystem (Kumar et al. 2016) is about $50 \%$ lower than in the North Sea (Dickey-Collas et al. 2010) or Norwegian Sea (Skaret $\&$ Pitcher 2016). The total standing biomass of all age classes of herring is approximately $3.5 \mathrm{t} \mathrm{km}^{-2}$ and the production is roughly $3 \mathrm{t} \mathrm{km}^{-2} \mathrm{yr}^{-1}$ (Kumar et al. 2016). Fig. 6 shows the dependence of the 9 major herring predators (herring in diet $>10 \%$ ) on forage species, including herring, eulachon, other forage fish, and krill. Pacific herring constitutes $>20 \%$ of the modelled diets of dolphins and porpoises (Delphinidae and Phocoenidae), humpback whales Megaptera novaeangliae, seals (Phocidae), and Pacific hake Merluccius productus, which implies that these predators could be particularly vulnerable to herring biomass changes. Following the Lenfest definitions (Pikitch et al. 2012), humpback whales are extremely dependent on forage species (forage species in diet $\geq 75 \%$ ), while 6 herring predators are highly dependent on forage species (forage species in diet $\geq 50 \%$ ) in the Haida Gwaii marine food web.

Modelled ecological impacts of the EwE MSE HCR scenarios (Table 1) are represented as percentage mean changes in functional group biomasses (see Fig. 8a) relative to the No FISHING base-

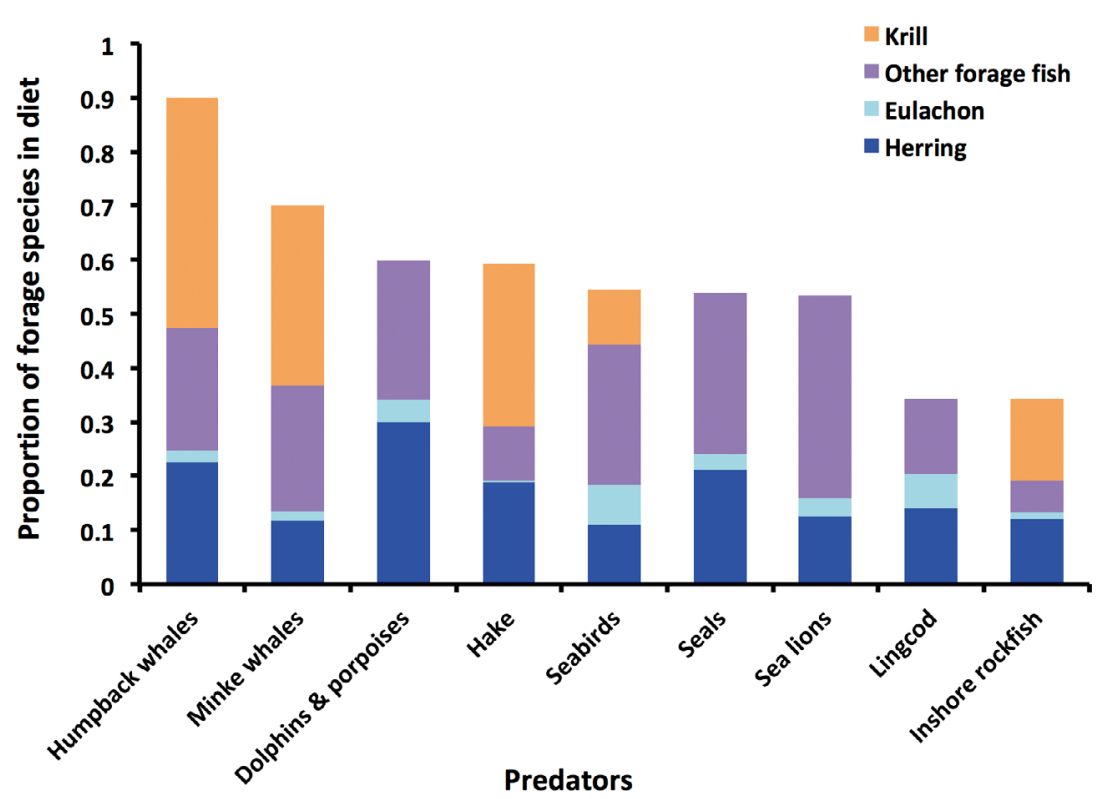

Fig. 6. Dietary dependence of the 9 major herring predators (herring in diet $>10 \%$ ) in the Haida Gwaii marine food web model on forage species: herring, eulachon, other forage fish, and krill line scenario (Fig. 7). Biomass changes were weaker for scenarios with lower herring fishing mortalities $(F)$, higher biomass cutoff thresholds $\left(B_{\mathrm{C}} / B_{0}\right)$, and step HCRs: No FISHING $\left(F=0 ; B_{\mathrm{C}} / B_{0}=\right.$ $100 \%)<\operatorname{SOK}\left(F=0.01 ; B_{\mathrm{C}} / B_{0}=100 \%\right)$ $<\{$ LENFEST $<B C<$ OPEN $\}\left(F=0.2 ; B_{\mathrm{C}} / B_{0}\right.$ $=40 \%>25 \%>0 \%)<M S Y\left(F_{\mathrm{MSY}} \approx 0.4\right.$; $B_{\mathrm{C}} / B_{0}=25 \%$ ). Regardless of HCR type and $B_{\mathrm{C}}$, which exhibited weaker effects than $F$, scenarios with $F<F_{\text {MSY }}$ did not disrupt food web structure, yielding biomass changes $<20 \%$ for all nonherring groups, whereas for $F=F_{\mathrm{MSY}}$, ecological impacts were stronger, with more intense biomass changes and more affected groups.

Ecological and socioeconomic risks of the EwE MSE scenarios associated with climate variability and climate shifts also were assessed. Under all HCR scenarios, the lowest quartile 


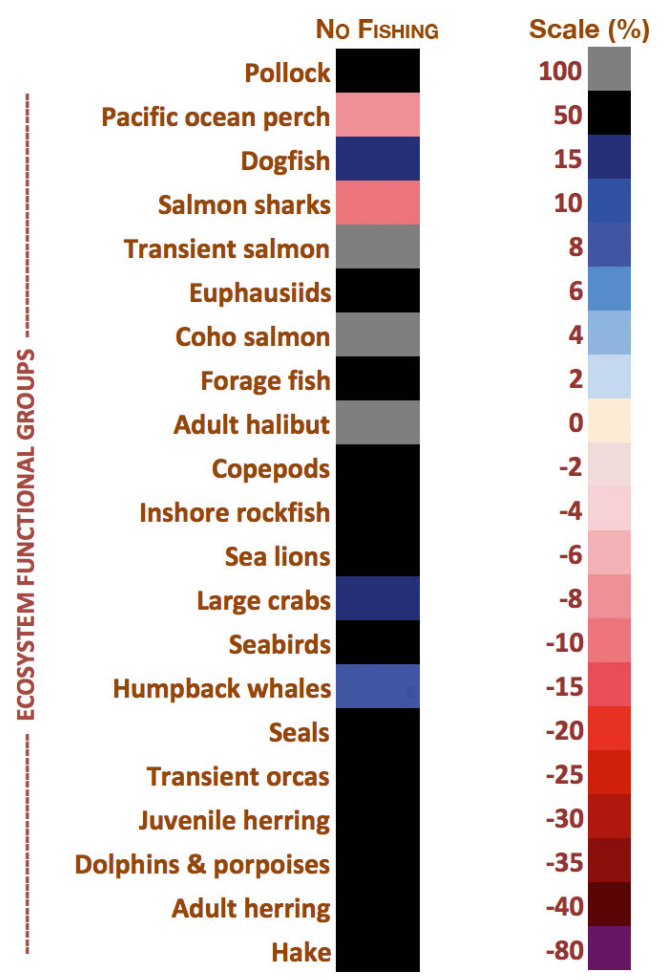

Fig. 7. Herring recovery and ecological impacts, depicted as percentage biomass changes from Ecopath model state for the NO FISHING baseline scenario: 100-yr MSE simulation with no commercial herring fishery, assuming all other fisheries at current harvest rates, no climate change, and a stable food web

biomass changes, reflecting the 1 -in-4 risks of poor biomasses, were strongly negative for most functional groups, suggesting the potential for substantial, adverse ecological impacts within the historical range of climate variability, with and without herring fishing (Fig. 8b). Simulated impacts of the $B C$ scenario under climate shifts, $B C_{0.75}$ and $B C_{0.25}$, drastically reduced most functional group biomasses (Fig. 8c). Modelled mean commercial herring catches correlated with high F scenarios: $M S Y>B C \approx O P E N>$ LENFEST > SOK (Fig. 9a). The probability of herring fishery closure was highest for LENFEST (due to high $\left.B_{\mathrm{C}} / B_{0}\right)>M S Y$ (due to high $F$ ) $>B C$, whereas the fishery is always open for the (constant-F) OPEN and SOK scenarios (Fig. 9b).

\subsection{VB approach: practical ethics}

From the value-ranking exercise (Table 2, Fig. 2), communal value landscapes showed no statistical difference between aggregated Haida Gwaii and herring industry results (Fig. 10, $\mathrm{n}_{\mathrm{HG}}=46, \mathrm{n}_{\mathrm{HI}}=25$;
Wilcoxon test $W=38$, df $=12, \mathrm{p}>0.6$ ). For both groups, respect and responsibility had the highest median ranks (ranked first by $59 \%$ and $46 \%$ of respondents in Haida Gwaii and by $48 \%$ and $44 \%$ in the herring industry, respectively), while sanctity and authority were the lowest ranked values. Overall, respondents chose a median of 4 rank levels (quartiles 3-10.5) and a mode of 12 , with $21 \%$ ranking values hierarchically (12 levels), and $8 \%$, equally (1 level).

Haida Gwaii and herring industry respondents, however, had strikingly different preferences (Fig. 11; $\left.\mathrm{n}_{\mathrm{HG}}=44 ; \mathrm{n}_{\mathrm{HI}}=24 ; G=30.2, \mathrm{df}=3 ; \mathrm{p}<0.0001\right)$ among the 4 herring fishery management scenarios (Table 1, Fig. 3). Haida Gwaii respondents stated their scenario preferences, in decreasing order, as $A$ whale of a time (no commercial herring fishery), The fish that get away (only commercial SOK fishery), and The little fish that could (commercial roe herring and SOK fisheries managed separately, with distinct HCRs); none chose Hard of herring (DFO policy). In contrast, herring industry respondents stated their scenario preferences, in decreasing order, as Hard of herring, The little fish that could, and A whale of a time, with none preferring The fish that get away.

In the cutoff threshold preference exercise, the Haida Gwaii $\left(\mathrm{n}_{\mathrm{HG}}=43\right)$ and herring industry $\left(\mathrm{n}_{\mathrm{HI}}=\right.$ 19) respondents again exhibited strikingly different preferences among the 5 cutoff thresholds for opening the commercial herring fishery (Fig. 12, $G=34.4$, df $=4 ; \mathrm{p}<0.0001)$. Most Haida Gwaii respondents preferred $B_{\mathrm{c}} / B_{0}=100 \%$, corresponding to no commercial herring fishery, followed by the approximate Lenfest recommendations for low and intermediate information, $B_{\mathrm{c}} / B_{0}=75 \%$ and $50 \%$, respectively; none preferred $B_{\mathrm{C}} / B_{0}=25 \%$, the DFO threshold, or $B_{\mathrm{c}} / B_{0}=0 \%$, where a commercial herring fishery would always be open. Among the herring industry respondents, the vast majority preferred the current DFO threshold, $B_{\mathrm{c}} / B_{0}=25 \%$, followed by $B_{\mathrm{c}} / B_{0}=$ $50 \%$ and $75 \%$, with none preferring $B_{\mathrm{c}} / B_{0}=100 \%$ or $0 \%$. Note that in the VB approach, not all research participants completed all exercises, generating variations in the sample sizes.

\subsection{VEBMA synthesis: science-policy table}

Our VEBMA results are synthesized in a sciencepolicy table (Table 3) designed as a deliberation and decision-support tool. We use a traffic-light colourcoding scheme to indicate the modelled ecological (Fig. 8) and socioeconomic (Fig. 9) impacts and risks and stated scenario (Fig. 11) and threshold (Fig. 12) 
a
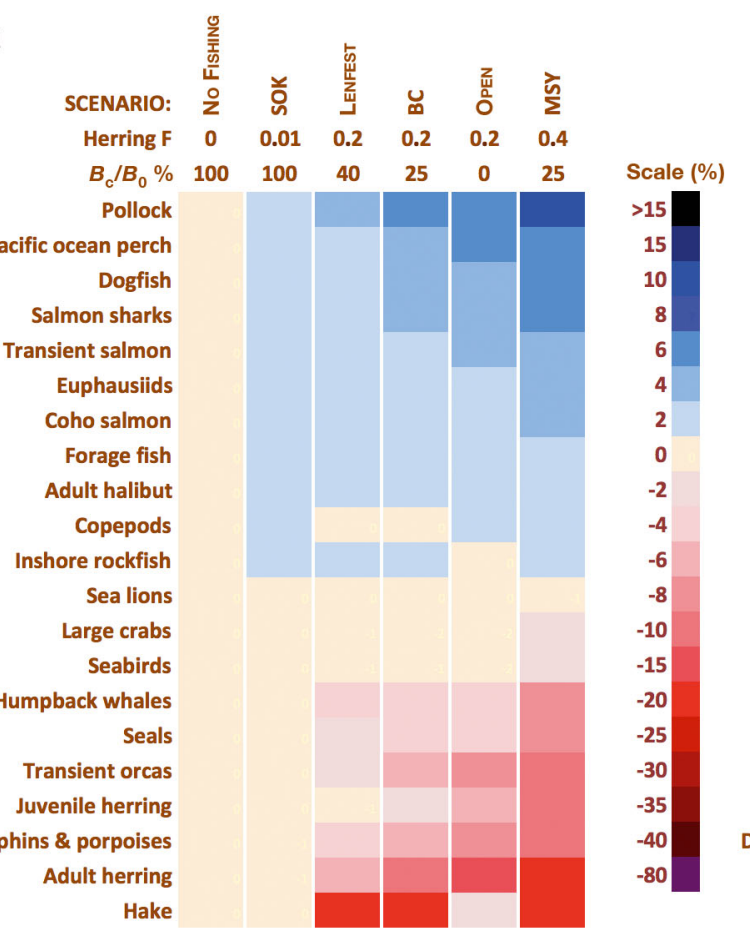

b
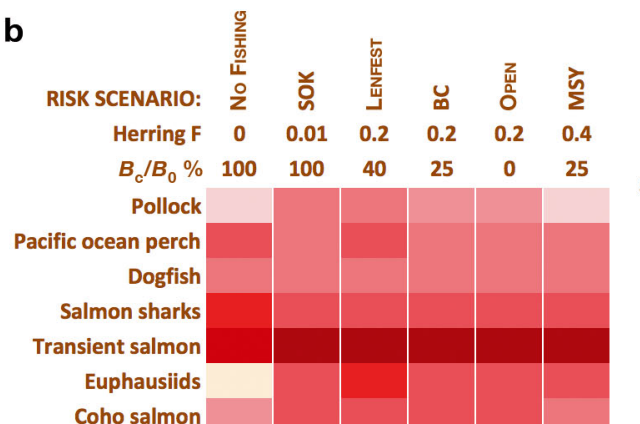

Coho salmon

Forage fish

Adult halibut

Copepods

Inshore rockfish

Sea lions

Large crabs

Seabirds

Humpback whales

Seals
Transient orcas

Juvenile herring

Dolphins \& porpoises

Adult herring

Hake

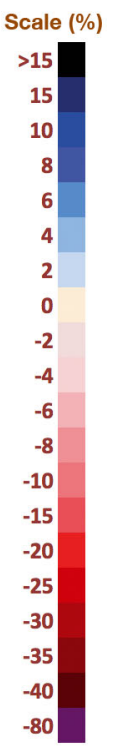

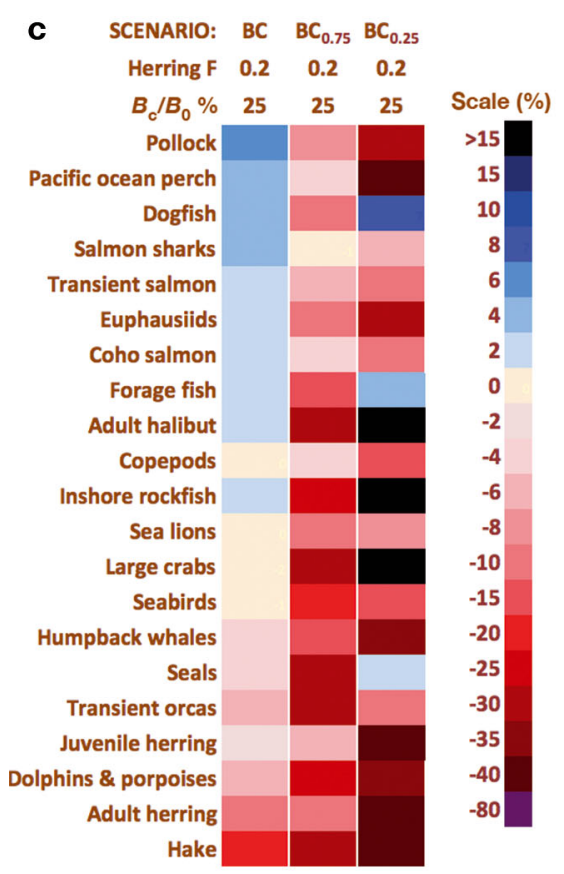

Fig. 8. (a) Modelled ecological impacts of the EwE MSE herring fishery management scenarios for constant fishing mortality, $F$, and step (constant $F$ with biomass cutoff thresholds, $B_{\mathrm{c}} / B_{0}$ ) harvest-control rules (HCRs; see Table 1). Impacts are expressed as percentage biomass changes, computed as (grand) means over $100 \mathrm{MSE}$ runs (100 yr each) for selected functional groups, relative to the no commercial herring fishery MSE baseline scenario (Fig. 7). Blue (red) denote positive (negative) biomass changes, while the colour intensity reflects the degree of change. The modelled HCR scenarios are, from left to right NO FISHING $\left(F=0, B_{\mathrm{c}} / B_{0}=100 \%\right) ; S O K$ $\left(F=0.01, B_{\mathrm{c}} / B_{0}=100 \%\right) ;$ LENFEST $\left(F=0.2, B_{\mathrm{c}} / B_{0}=40 \%\right) ; B C(F=0.2$ ， $\left.B_{\mathrm{c}} / B_{0}=25 \%\right) ; \operatorname{OPEN}\left(F=0.2, B_{\mathrm{c}} / B_{0}=0 \%\right) ;$ and $M S Y\left(F_{\mathrm{MSY}} \approx 0.4 ; B_{\mathrm{c}} / B_{0}=\right.$ $25 \%$ ). (b) For the EwE MSE HCR scenarios in (a), ecological risks of low biomasses from climate variability, expressed as first quartile biomass changes, i.e. 1-in-4 risk of low biomasses from climate-driven phytoplankton biomass variability (and herring stock assessment errors). (c) For the $B C$ scenario $\left(F=0.2, B_{\mathrm{c}} / B_{0}=25 \%\right)$, ecological risks of climate shift scenarios, showing means of functional group biomasses simulated by resampling phytoplankton biomasses from only below the third quartile of the historical distribution ( $B C_{0.75}$, 'no good primary production years') and only below the first quartile $\left(B C_{0.25}\right.$, 'only bad primary production years') preferences of the Haida Gwaii community, disaggregated also for Haida and commercial herring fishers, and herring industry respondents outside of Haida Gwaii. The ecological viability of the scenarios, deduced from proxies such as modelled herring biomass and recovery, humpback whale recovery, marine food web structure, and climate variability and shift risks, is compared with their socioeconomic feasibility assessed from their mean herring catches and probability of fishery closure, and societal desirability, as gauged from community and industry stakeholder preferences.

Table 3 also indicates the quality of our VEBMA results. In the EB approach, the $70 \%$ threshold results 

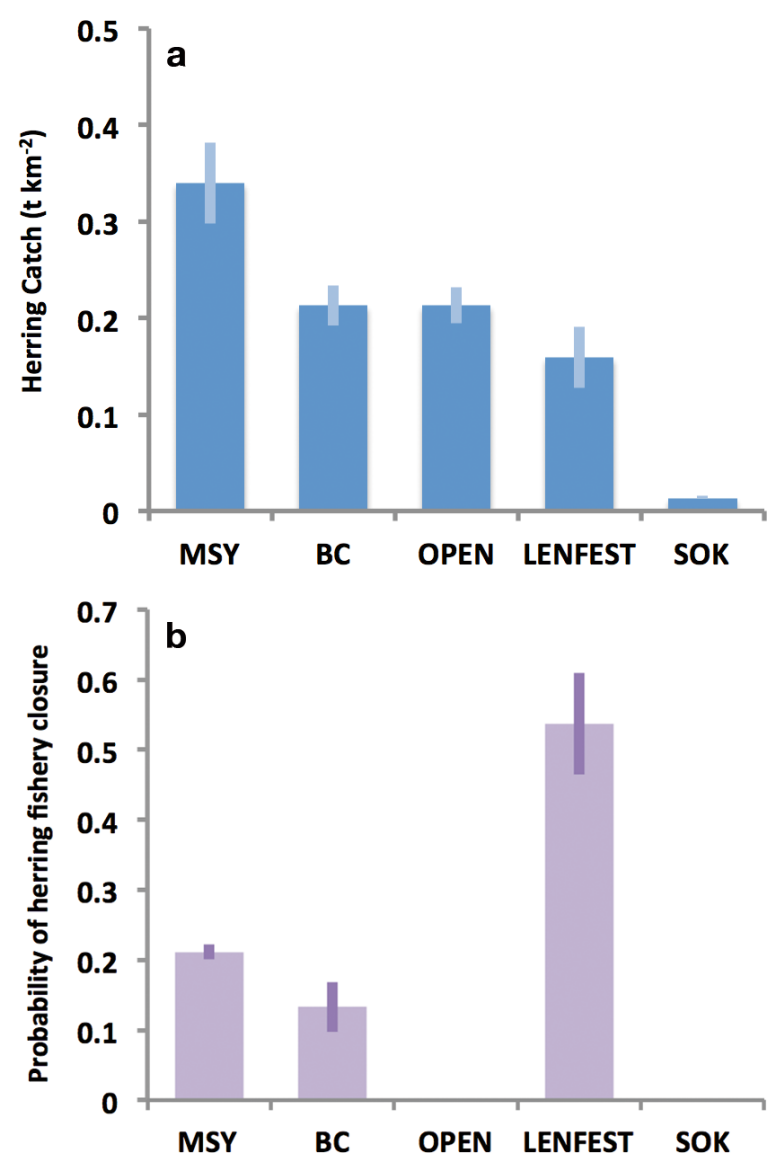

Fig. 9. (a) Mean herring catches for the MSE scenarios, with 95\% confidence limits calculated from standard deviations. (b) Probabilities of commercial herring fishery closure for the MSE scenarios (for the OPEN and SOK scenarios with constant $F$, the fishery is always open), with $95 \%$ confidence limits calculated from quartiles of the herring biomasses are from an older version of the EwE model, so have medium quality (notably, a newer version of the model yielded comparable results; Surma 2019), while the risks from climate variability and shift were not explicitly modelled for the non- $B C$ scenarios, and therefore have lower quality. There are no ecological modelling results for the Little fish that could scenario, labelled here as $R O E \& S O K$, as the HCRs were not quantitatively specified for this qualitative scenario. In the VB approach, the herring industry results came from fewer respondents, so have medium quality.

\section{DISCUSSION}

\subsection{VEBMA methodological reflections}

VEBMA is a highly innovative, transdisciplinary methodology. As such, it needs refinement to our proof-of-concept introduced here. For example, we recognize that some bias may have been introduced by how the values and scenarios were selected, named, and depicted (Tables 1 \& 2, Figs. 2 \& 3), but given the fishery conflict, their co-construction within a participatory setting with representatives of all stakeholder groups, including affected communities, industry, and fisheries agencies, was not feasible. Despite this, we witnessed clear benefits of the artwork and scenario names in engaging research participants and triggering them with multiple cues. Both cognitive and affective modalities likely elicited in them a wider range of knowledge and experiences to draw upon when reflecting on their subjective values and perspectives on the fishery.
Fig. 10. Median ranks of 12 values (Table 2, Fig. 2) aggregated from value rankings of the Haida Gwaii $\left(\mathrm{n}_{\mathrm{HG}}=46\right)$ and herring industry $\left(\mathrm{n}_{\mathrm{HI}}=25\right)$ respondents, showing uncertainty in the communal value landscapes by first quartiles ( $W=$ $38, \mathrm{df}=12, \mathrm{p}>0.6)$

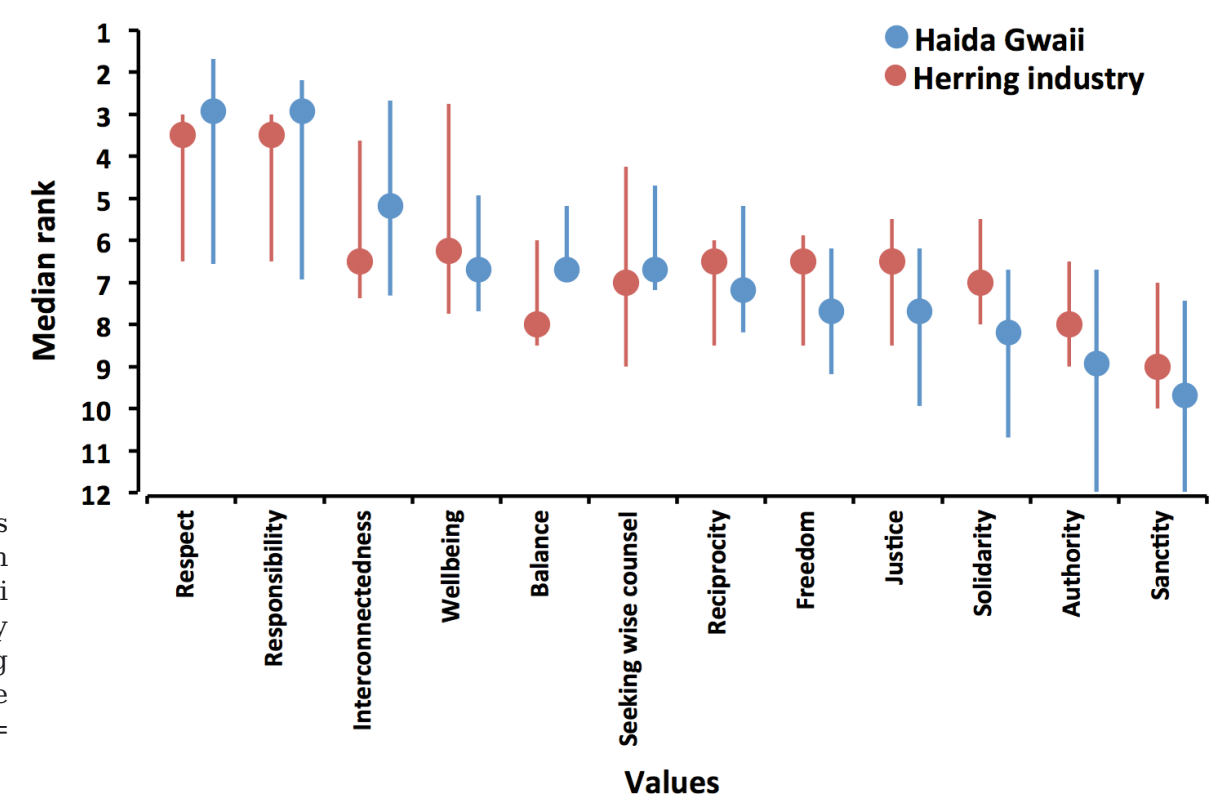




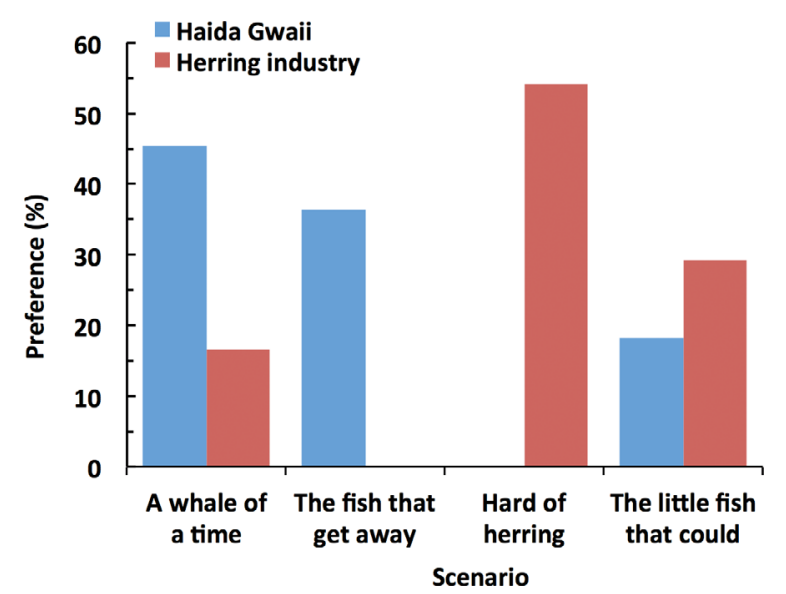

Fig. 11. Stated preferences among 4 herring fishery management scenarios (Table 1, Fig. 3) of Haida Gwaii $\left(\mathrm{n}_{\mathrm{HG}}=\right.$ $44)$ and herring industry $\left(\mathrm{n}_{\mathrm{HI}}=24\right)$ respondents $(G=30.2$, $\mathrm{df}=3, \mathrm{p}<0.0001)$

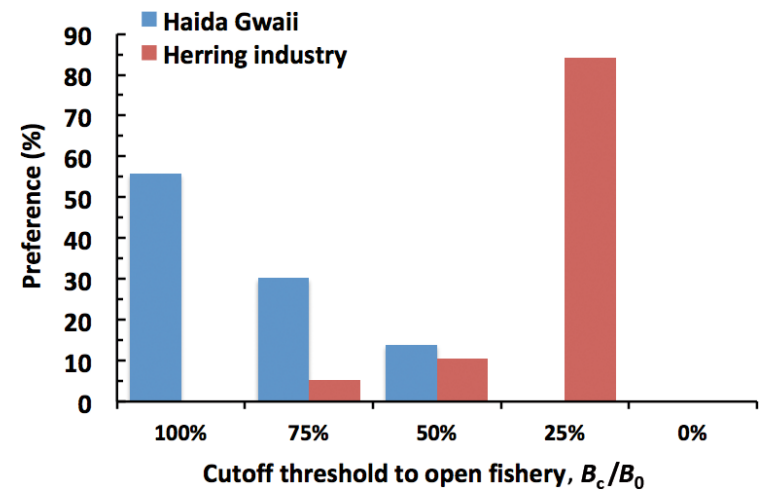

Fig. 12. Stated preferences among 5 cutoff thresholds, $B_{\mathrm{c}}$, for opening the commercial herring fishery, expressed as percentages of the estimated unfished biomass, $B_{0}$, of Haida Gwaii $\left(\mathrm{n}_{\mathrm{HG}}=43\right)$ and herring industry $\left(\mathrm{n}_{\mathrm{HI}}=19\right)$ respondents $(G=34.4, \mathrm{df}=4, \mathrm{p}<0.0001)$

When asked if the value images influenced their rankings, only 1 respondent, with a background in marketing, said yes, referring to their subliminal effects, whereas another focused exclusively on the images, not the text, in describing the values. Although participant self-reports and researcher observations are no substitute for rigorous controls in methodological design, they do suggest that the images likely did not prime the subjects in their value rankings. On the contrary, we observed the direct benefits of using art in our VEBMA methodology as an engagement and communication tool: participants often reacted positively to the artwork and asked if they could keep the value cards after the interviews, while academic and public audiences of our research presentations appreciated the images and the 'catchy' names.
While we did not rigorously test for potential bias of the scenario names or images, we draw tentative conclusions from observations made in the course of the workshops and interviews. In the Haida Gwaii community workshops, individual participants' responses to the question 'How do you think the Haida Gwaii herring fishery should be managed?', posed at both the beginning and end of the workshop, did not change qualitatively. Individual views were thus stable to possible priming by the scenario names and images, as well as to group discussions. Also, despite consistent methodological materials and protocols, the Haida Gwaii community and herring industry members exhibited common value rankings (Fig. 10), but strikingly distinct scenario preferences (Figs. 11 \& 12), suggesting that their scenario choices were biased not by the names or images, but rather by their pre-existing concerns, attitudes, and beliefs about the fishery. Individuals have an identity-protective cognition bias that tends to preserve their cultural identity and beliefs (Kahan et al. 2007, Kahan 2010), which was likely manifest in our research participants.

Scenario design and translation between scenarios and policy choices is not straightforward. Scenarios are 'plausible, challenging, and relevant stories about how the future might unfold, which can be told in both words and numbers; ' they help envision future pathways and attempt to account for critical uncertainties (Raskin et al. 2005, p. 35). Translating narrative scenarios into quantitative assessments is complex (Mallampalli et al. 2016), so we designed roughly equivalent EB and VB scenarios (Table 1) and asked research participants to describe their preferences. For the EB scenarios, precise HCRs had to be specified to perform the ecosystem modelling, whereas for the VB scenarios, qualitative descriptions that highlighted the diverse values of herring were paired with quantitative cutoff thresholds that could be modelled. This ambiguity among the quantitative and qualitative scenarios creates space for dialogue and interpretation among diverse perspectives, particularly between 'expert' scientists and 'lay' citizens, by embracing epistemological uncertainties in the scenario designations to equalize participants and engage participation.

Respondents' scenario and threshold preferences can be compared for self-consistency, given their correspondences (Table 1, Figs. 11 \& 12), i.e. A whale of a time and The fish that get away both correspond to $B_{\mathrm{c}} / B_{0}=100 \%$ for the roe herring fishery, while Hard of herring corresponds to $B_{\mathrm{c}} / B_{0}=25 \%$. Of the 20 Haida Gwaii respondents who chose $A$ whale of a time, $74 \%$ chose the corresponding $B_{\mathrm{c}} / B_{0}=100 \%$ 
Table 3. VEBMA science-policy table, a deliberation and decision-support tool, for the Haida Gwaii herring fishery, synthesizing the ecosystem-based (EB) and value-based (VB) results in Figs. 8 \& 9 and 11 \& 12, respectively. The quantitative and qualitative fishery management scenarios (Table 1) are given the rough equivalence: No FISHING corresponds to $F=0$ and $A$ whale of a time; SOK to $F=0.01$ and The fish that get away; LENFEST PRECAUT to $F=0.2, B_{\mathrm{c}} / B_{0}=70-75 \%$; LENFEST to $F=0.2, B_{\mathrm{c}} / B_{0}=$ $40-50 \%$; $B C$ to $F=0.2, B_{\mathrm{c}} / B_{0}=25 \%$ and Hard of herring; OPEN to $F=0.2, B_{\mathrm{c}} / B_{0}=0 \%$; and "ROE \& SOK" to The little fish that could (quotation marks denote that this scenario could not be modelled, as HCRs were not quantitatively specified). Green indicates low ecological or positive socioeconomic impact or risk (in the EB approach) and a strong stated preference (in the VB approach), red shows high ecological or negative socioeconomic impact or risk (EB) and is not preferred (VB), while olive, grey, and orange colours denote intermediate states, ranging from less to more ecological or better to worse socioeconomic impact or risk (EB) and more to less desirable (VB). The quality of the information sources or knowledge used in the evaluation is indicated by block letters in the upper-right-hand corner of each cell: L, M, and H denote low, medium, and high quality, respectively. The impacts and risks assessed by the EB approach are various proxies of ecosystem or socioeconomic status deduced from simulated biomass changes over the EwE MSE runs: 'Sustainable herring biomass' represents the standing herring biomass; 'Herring recovery' represents the trend in herring biomass; 'Humpback whale recovery' represents the trend in humpback whale biomass; 'Marine food web structure' represents the cumulative impacts on all functional groups; 'Climate variability risks' represent the aggregated functional group biomass response to stochastic inter-annual variance in the primary production; 'Climate shift risks' represent biomass responses to a reduction in the primary production (mean climate) over time; 'Herring catch' represents the mean herring catch modelled in the MSE scenarios; and 'Fishery closure' represents the probability of fishery closure estimated from the modelled herring biomass compared to the cutoff threshold. The stated preferences of the 'Haida Gwaii (HG) community', '(Indigenous) Haida in HG', 'Commercial fishers in HG' and 'Herring industry outside $\mathrm{HG}^{\prime}$ are from the semi-structured interviews conducted within the VB component of the VEBMA study

\begin{tabular}{|c|c|c|c|c|c|c|c|c|}
\hline \multirow{4}{*}{ 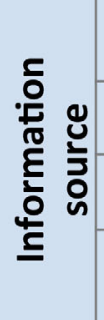 } & SCENARIO & $\begin{array}{c}\text { No } \\
\text { FISHING }\end{array}$ & SOK & $\begin{array}{l}\text { LENFEST } \\
\text { PRECAUT }\end{array}$ & LENFEST & $B C$ & OPEN & $\begin{array}{l}\text { "ROE \& } \\
\text { SOK" }\end{array}$ \\
\hline & Fishing mortality, F & 0 & 0.01 & 0.2 & 0.2 & 0.2 & 0.2 & $?$ \\
\hline & Cutoff threshold, $B_{c} / B_{0}$ & $100 \%$ & $100 \%$ & $70-75 \%$ & $40-50 \%$ & $25 \%$ & $0 \%$ & $?$ \\
\hline & Focal value & Ecological & Cultural & Ecological & Ecological & $\begin{array}{l}\text { Socio- } \\
\text { economic }\end{array}$ & $\begin{array}{l}\text { Socio- } \\
\text { economic }\end{array}$ & Plural \\
\hline \multirow{8}{*}{ 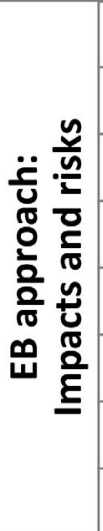 } & Sustainable herring biomass & H & $\mathrm{H}$ & $M$ & H & $\mathrm{H}$ & H & \\
\hline & Herring recovery & HI & H & M & $\mathrm{H}$ & H & H & \\
\hline & Humpback whale recovery & H & H & $M$ & $H$ & H & H & \\
\hline & Marine food web structure & H & $\mathrm{H}$ & $M$ & H & H & H & \\
\hline & Climate variability risks & $M$ & M & $\mathrm{L}$ & $\mathrm{L}$ & H & H & \\
\hline & Climate shift risks & M & M & $\mathrm{L}$ & L & H & H & \\
\hline & Herring catch & H & H & M & M] & M & H & \\
\hline & Fishery closure & H & H & $\mathrm{M}$ & $M$ & $\mathrm{MI}$ & H & \\
\hline \multirow{4}{*}{ 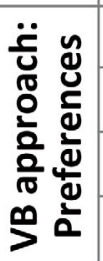 } & Haida Gwaii (HG) community & H & H] & H & H & $\mathrm{H}$ & $\mathrm{H}$ & \\
\hline & (Indigenous) Haida in HG & H & $H$ & HI & $H$ & H & H & \\
\hline & Commercial fishers in HG & H & H] & H & $\mathrm{H}$ & H & H & \\
\hline & Herring industry outside HG & $\mathrm{M}$ & M & $\mathrm{M}$ & MI & M & M & M \\
\hline
\end{tabular}

$(G=38.8, \mathrm{df}=1, \mathrm{p}=0.001)$, while of the 13 herring industry respondents who chose Hard of herring, all 11 who chose a threshold (85\%) selected the corresponding $B_{\mathrm{c}} / B_{0}=25 \%(G=6.9, \mathrm{df}=1, \mathrm{p}=0.005)$. This shows that stated scenario and threshold preferences are largely self-consistent, which internally validates the methodology.
By using an illustrated, comprehensive, and resonant set of values (Table 2, Fig. 2) in relation to fishery management scenarios, VEBMA engaged diverse participants in meaningful discussions about their values and management preferences. When asked, only a few respondents suggested additional values (e.g. peace), affirming the 'fitness-for-purpose' (Fun- 
towicz \& Ravetz 1990, Ravetz 1996) of our value set. Notably, however, the value rankings or communal 'value landscapes' of the Haida Gwaii community and the herring industry were similar, while their management preferences differed strikingly, suggesting that the issues underlying the fishery conflict are highly complex and potentially contradictory to stakeholder values. Values may run counter to other interests in some settings, particularly in the highly politicized contexts of resource conflicts. Also, respondents can have similar overarching values but may interpret or apply them differently, depending on local circumstances and the differential benefits and impacts accrued from herring. VEBMA is being refined to address these issues, by exploring the cultural contextualization of values and how values may translate to principles of management (Lam 2016a), and by investigating factors and strategies that may influence how individuals negotiate tradeoffs among multiple desirable priorities for the environment (e.g. Loring \& Hinzman 2018). These refinements notwithstanding, the proof-of-concept VEBMA methodology introduced here is an innovative approach that can promote dialogue and transparent decision-making to resolve policy tradeoffs and value conflicts in resource management as decribed in the subsequent sections.

\subsection{Ecological implications}

EwE ecosystem simulation modelling shows that Pacific herring is an important prey species for various Haida Gwaii or Northeast Pacific predators, particularly hake and marine mammals (Fig. 5). For predators whose modelled diets comprise $\geq 20 \%$ herring, i.e. dolphins and porpoises, humpback whales, and seals (Fig. 6), as well as top predators (transient orcas Orcinus orca), strong declines of $\geq 35 \%$ baseline values were observed in response to simulated collapse (95\% depletion) of herring (Surma et al. 2018b). This reveals strong potential impacts of herring overfishing that could cascade through predator populations and food web structure (Fig. 4). From the massbalanced EwE modelling, herring's status as a key forage fish in this ecosystem is equivocal, given its low SURF index value, but strong biomass declines in $15 \%$ of non-herring groups upon simulated herring depletion. This reflects the Northeast Pacific food web's diverse forage fish guild (herring, eulachon, sandlance, capelin, smelts, etc.) and generalist feeding strategies of most herring predators. Energybalanced EwE modelling, however, indicates that
Pacific herring is an important energy node in this food web (Surma et al. 2018a), corroborating other studies (e.g. Perez 1994, Anthony et al. 2000, Vollenweider et al. 2011) that place adult herring among the most energy-rich prey species in the subarctic North Pacific.

Herring fishery management strategies with low $F$ and high $B_{\mathrm{c}}$ (Table 1 ) are conducive to precautionary and ecosystem-based fisheries management, corroborating the Lenfest findings, while the MSY strategies typically employed in Europe, albeit within a precautionary approach, are less so (Fig. 8a). Notably, the non-capture SOK fishery traditionally practiced by coastal BC First Nations has minimal ecological impacts and the $B C$ scenario has only modest impacts, although these could become strongly adverse under the existing degree of climate variability (Fig. 8b) and especially projected climate shifts (Fig. 8c). Fishery impacts on herring and its predators are exacerbated by poor primary production and stock assessment errors, which shows the influence of both top-down and bottom-up processes on Pacific herring trophodynamics and the need for precautionary management (Surma et al. 2018b).

Ecosystem modelling demonstrates the critical role of herring in the Northeast Pacific food web and suggests that a foremost consideration in selecting herring fishery management strategies or policy options should be their impacts on not only herring populations, but also ecosystem health. In Table 3, we list some species-specific indicators derived from the MSE outputs, such as herring biomass and recovery and humpback whale recovery. In addition, we examine the impacts of the management scenarios on the marine food web, evaluated as the cumulative impacts on the biomasses of all functional groups. Composite ecosystem health indicators could be based on functional group biomass or primary production thresholds. Proposed ecosystem thresholds derived from emergent properties of marine ecosystems include cumulative biomass and cumulative production curves (Link et al. 2015). Here, we simply use the MSE biomass outputs as proxies for ecosystem status that should be prioritized above stakeholder preferences in fishery decision-making and policy setting, if sustainable management is a guiding norm.

\subsection{Management implications}

Most Haida Gwaii respondents preferred no commercial herring fishery, at least until herring have sufficiently recovered, followed by only a commer- 
cial SOK fishery, which, being non-capture, is more ecologically sustainable and is also a traditional food source (Fig. 11). They similarly preferred the precautionary cutoff thresholds for opening the commercial fishery (Fig. 12). Thus, Haida Gwaii respondents preferred the scenarios modelled to have the least ecological impacts and risks (Table 3 ). This likely reflects the vulnerability of the community to ecological and cultural impacts from re-opening the Haida Gwaii herring fishery and low socioeconomic benefit under the current license structure and distribution. None of the Haida Gwaii respondents selected the DFO policy or threshold, indicating that they clearly desire a change. When asked, 'How do you think the Haida Gwaii herring fishery should be managed?,' $70 \%$ expressed a preference for co-management or full Haida control.

In contrast, herring industry respondents showed satisfaction with the DFO policy, with strong preferences for the DFO strategy and cutoff threshold (Figs. 11 \& 12). This may reflect the fact that the industry, through the Herring Conservation and Research Society, partners with the DFO to conduct herring research, assessment, and management activities. Our modelling suggests that the DFO policy is precautionary under existing conditions, with fairly modest ecosystem impacts that could be further reduced with a higher cutoff threshold, but is not precautionary against risks of climate variability and change (Table 3). The local commercial herring fishery catch is approximately $0.25 \mathrm{t} \mathrm{km}^{-2} \mathrm{yr}^{-1}$ (Kumar et al. 2016), equivalent to roughly $12.5 \%$ of the natural mortality, $M$, and $1 / 4$ of the forage fish catch recommended by Lenfest $(\leq 50 \% M)$ (Pikitch et al. 2012). With the Lenfest recommended higher $B_{\mathrm{c}} / B_{0}$ of $40 \%$, the probability of fishery closure is much higher than with the $25 \%$ threshold (Fig. 9b), which would lead to undesirable socioeconomic instability and unpredictability for commercial fishers.

\subsection{Policy implications}

VEBMA was developed amidst BC's Pacific herring fishery conflict to encourage evidence-informed policy that considers the ecological, socioeconomic, and cultural values of herring to diverse stakeholders. To resolve the conflict, an alternative pathway is needed that does not alienate any of the stakeholder groups. As the foundation for sustainable fisheries, however, considerations of the ecosystem impacts of alternative management strategies must trump the preferences of all stakeholders. A consilient way forward would consider the common value priorities (Fig. 10) and management preferences (Figs. 11 \& 12) of local stakeholders, while also considering the ecological, socioeconomic, and cultural impacts and risks of alternative policy options (Figs. 8 \& 9), as synthesized in the VEBMA science-policy table (Table 3). This contrasts with the decision tables often used in participatory fisheries management (Fulton et al. 2014, Punt et al. 2016) and structured decision-making (Gregory et al. 2012) in that it does not offer decision rules, but rather is designed to make transparent ecological and socioeconomic impacts and risks and societal preferences to facilitate stakeholder dialogue and collaborative decision-making. The least desirable policy option would be the OPEN or always fishing scenario (preferred by none and with the highest target species and ecological impacts). The DFO policy (preferred by only 1 of the 2 stakeholder groups and with high ecological impacts) would be the next least favourable, followed by only a commercial SOK fishery (not preferred by 1 group, despite low ecological impacts). Both these policy options would likely sustain the current fishery conflict, given the divergent preferences. The next least favoured options, in descending order, are the 2 Lenfest recommended and precautionary cutoff thresholds for intermediate and low information, respectively, and no fishing. This suggests that maintaining the current fishery closure, which was preferred by some members from both groups and has the least ecological impacts, is optimal now.

To illustrate some of the tradeoffs that must be considered when making Pacific herring fishery policy decisions in Haida Gwaii, we look at the no commercial herring fishery scenario in more detail. As seen in Figs. 4 to 6, herring is an important prey species to humpback whales, a charismatic species. Modelled whale population recovery from historical depletion of Northeast Pacific food webs and fisheries resulted in declines of up to $87 \%$ in Pacific herring and $72 \%$ for piscivorous rockfish (Sebastes spp.), as well as cascading effects on many demersal fish groups (Surma \& Pitcher 2015). Simulating the impacts of the 4 herring fishery management scenarios on humpback whale recovery reveals that commercial herring fishing does not prevent, but does impede, its recovery (Fig. 13). For humpback whales to increase from $500 \mathrm{t}$ to $900 \mathrm{t}$, for example, it takes $42,43,51$, and $56 \mathrm{yr}$ in the NO FISHING, SOK, LENFEST, and BC scenarios, respectively, corresponding to delays of 1, 9, and $14 \mathrm{yr}$ compared with no commercial fishing. A commercial herring fishery closure, however, results in foregone fishing revenue for the herring industry 


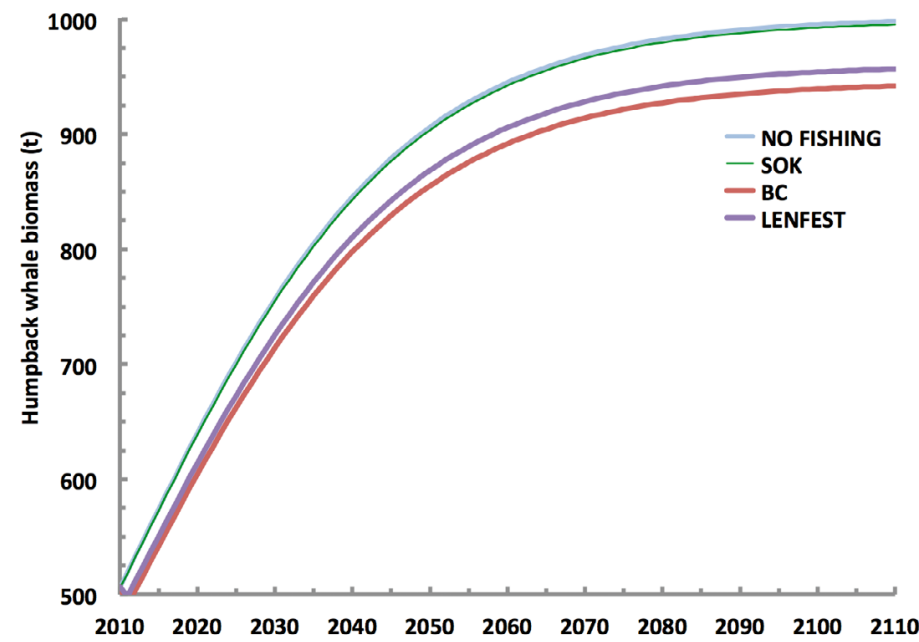

Fig. 13. One herring fishery policy tradeoff: Impact on humpback whale recovery in the Haida Gwaii marine food web of alternative herring fishery management scenarios

(wholesale value of $\$ 68.7$ million CDN in 2017; British Columbia Ministry of Agriculture 2019), but could lead to growth in ecotourism revenue with more humpback whale sightings. There also would be more herring available for First Nations food, social and ceremonial allocation of SOK, described by 1 Haida interviewee as 'soul food and sustenance for us.' The VEBMA science-policy table (Table 3) makes transparent such policy tradeoffs to facilitate evidence-informed and inclusive decision-making.

For sustainable management of a desirable and viable herring fishery in the future, we recommend exploring the compromise option of managing the roe herring and SOK fisheries separately, with distinct HCRs, and cutoff thresholds between 25 and $75 \%$. More specifically, given the complete dissatisfaction of Haida Gwaii community members with the $25 \%$ threshold (Fig. 12) and the high probability of fishery closure for the Lenfest recommended $40 \%$ threshold (Fig. 9b), we propose more precautionary EBFM strategies within the narrower range of $B_{\mathrm{c}} / B_{0}=$ $30-35 \%$ for the roe herring fishery and $<30 \%$ for the SOK fishery. The precise thresholds and HCRs should be decided within a participatory setting with DFO and the herring industry, affected local and indigenous communities, and other stakeholders, informed by ecosystem simulation modelling to evaluate their ecological and socioeconomic impacts and risks. Note that since this research was completed, and perhaps partially in response to it, DFO scientists have recommended a cutoff threshold of $30 \%$ to avoid 'serious harm' to the BC Pacific herring stocks (Kronlund et al. 2018).

\subsection{Governance implications}

VEBMA resonates with the 'post-normal science' approach (Funtowicz \& Ravetz 1993, Gluckman 2014) to wicked problems at the science-policy interface, where facts are uncertain, values are in dispute, stakes are high, and decisions are urgent. In fisheries, despite this uncertainty and complexity (Ludwig et al. 1993, Pikitch et al. 2004), contested decisions surrounding fishery openings, total allowable catches, and quota shares must be made before each fishing season (Hauge 2011, Dankel et al. 2012). To facilitate ethical governance (Lam \& Pauly 2010, Lam \& Pitcher 2012), we sought input from an 'extended peer community' across academic disciplines, local and indigenous communities, industry, government, and civil society. To better inform decision-making among the fishery policy choices, the quality of the knowledge (EB impacts and risks and VB preferences) was assessed and displayed in the upper right hand corner of each cell in the VEBMA science-policy table (Table 3).

By integrating the values, knowledge, and perspectives of stakeholders with ecosystem considerations to set management objectives and strategies, VEBMA delivers a generalizable deliberation and decision-support tool, with particular merit when values or interests conflict. Making explicit the plurality of values that permeate the science-policy interface can reduce politically biased decision-making. VEBMA also reduces outcome uncertainty (Punt et al. 2016) by exposing values and potential sources of conflict that are masked when stakeholders advocate for specific management strategies. The VEBMA science-policy table reveals the differential impacts of policy options on society and the ecosystem to help decision-makers resolve fishery tradeoffs and conflicts. It can foster dialogue and deliberation among stakeholders affected by resource decisions, such as local communities, industry, NGOs, scientists, managers, and policy makers. VEBMA thus synthesizes and explicates diverse knowledge and value perspectives to foster accountability, trust, and ultimately, ethical governance.

Acknowledgements. We gratefully acknowledge the Haida Gwaii and herring industry research participants for so generously sharing their time, experiences, and perspectives; the Council of the Haida Nation (particularly Russ Jones, Catherine Rigg, and Molly Clarkson); the Herring Industry Advisory Council, notably Greg Thomas; and retired fisherman Joe Bauer. We thank Kate Millar and Sahir Advani for contributing to the Haida Gwaii workshops and for being sounding boards for the values research, Jim McIsaac for his comments on an early draft, and Thomas Potthast for his 
feedback on an earlier version of our manuscript and fruitful discussions on values and ethics. We appreciate also the comments and consequent improvements to the manuscript from the 4 anonymous reviewers, the Theme Section guest editors, and the MEPS editorial staff.

This research was co-funded by the following: University of British Columbia Peter Wall Institute for Advanced Studies Solutions Initiative Project, Collaborative Solutions for Haida Gwaii Herring Fisheries (VEBMA conceptualization \& VB research in Haida Gwaii; Principal Investigators [PIs]: M.E.L., T.J.P. \& E.A.P.); Natural Sciences and Engineering Research Council of Canada (NSERC) Strategic Partnership Grant, Understanding the Ecosystem Role of Pacific Herring in Coupled Social-ecological Systems: Advancing Forage Fish Science (\#447247) (EB research \& VEBMA science-policy synthesis; PI: T.J.P.); NSERC Discovery Grant, The Dynamics and Restoration Ecology of Marine Ecosystems (\#1409792012 RGPIN) (VEBMA synthesis; PI: T.J.P.); Mitacs Accelerate Grant, Identifying Stakeholder Values in British Columbia Herring Fisheries, supported by the T. Buck Suzuki Environmental Foundation and Skipper Otto's Community-supported Fishery (VB research with herring industry stakeholders; PI: M.E.L.); University of British Columbia Sustainability Research Grant, Fostering Sustainable British Columbia Herring Fisheries with Cultural Narratives and Images (culturally responsive artwork; PIs: M.E.L., T.J.P. \& E.A.P.); and European Commission Marie Skłodowska-Curie Individual Fellowship project, Enhancing Seafood Ethics and Sustainability (eSEAS): A Values and Ecosystem-based Management Approach (\#753937) (VEBMA analysis and ethical governance; PIs: M.E.L. \& M.K.). University of British Columbia Behavioural Research Ethics Board approval was obtained for the participatory research: certificate \#H15-00525.

\section{LITERATURE CITED}

Adams PB (1980) Life history patterns in marine fishes and their consequences for fisheries management. Fish Bull 78:1-12

* Ainsworth CH, Pitcher TJ, Heymans JJ, Vasconcellos M (2008) Reconstructing historical marine ecosystems using food web models: Northern British Columbia from preEuropean contact to present. Ecol Modell 216:354-368

Arnstein SR (1969) A ladder of citizen participation. J Am Plan Assoc 35:216-224

Anthony JA, Roby DD, Turco KR (2000) Lipid content and energy density of forage fishes from the northern Gulf of Alaska. J Exp Mar Bio Ecol 248:53-78

Baum JK, Fuller SD (2016) Canada's marine fisheries: status, recovery potential and pathways to success. Oceana Report. University of Victoria

Beattie A (1999) The Hecate Strait: a preliminary model. In Haggan N, Beattie A (eds) Back to the future: reconstructing the Hecate Strait ecosystem. Uni B C Fish Cen Res Rep 7(3)

Berkes F (2012) Implementing ecosystem-based management: Evolution or revolution? Fish Fish 13:465-476

Bremer S, Haque MM, Haugen AS, Kaiser M (2016) Inclusive governance of aquaculture value-chains: co-producing sustainability standards for Bangladeshi shrimp and prawns. Ocean Coast Manage 131:13-24

British Columbia Ministry of Agriculture (2019) British Columbia seafood industry: year in review 2017. https:// www2.gov.bc.ca/assets/gov/farming-natural-resourcesand-industry/agriculture-and-seafood/statistics/industry- and-sector-profiles/year-in-review/bcseafood_yearinreview _2017.pdf

Brosch T, Sander D (eds) (2016a) Handbook of value: perspectives from economics, neurosciences, philosophy, psychology, and sociology. Oxford University Press, Oxford

Brosch T, Sander D (2016b) From values to valuation: an interdisciplinary approach to the study of values. In: Brosch T, Sander D (eds) Handbook of value: perspectives from economics, neuroscience, philosophy, psychology, and sociology. Oxford University Press, Oxford, p 397-404

Browman HI, Stergiou KI (eds) (2004) Perspectives on ecosystem-based approaches to the management of marine resources. Mar Ecol Prog Ser 274:269-303

*Bowman HI, Stergiou KI (eds) (2005) Politics and socioeconomics of ecosystem-based management of marine resources. Mar Ecol Prog Ser 300:241-296

Canada. Department of Justice (2013) A consolidation of the Constitution Acts, 1867 to 1982. Cat. No.: YX1-1/2012 http://publications.gc.ca/site/eng/9.697617/publication. html

Carlson S (2005) Changes in roe herring markets: a review of available evidence. CFEC Report Number 05-5N. Commercial Fisheries Entry Commission, Juneau, AK

* Chan KMA, Balvanera P, Benessaiah K, Chapman M and others (2016) Why protect nature? Rethinking values and the environment. Proc Natl Acad Sci USA 113:1462-1465

* Chan KAM, Gould RK, Pascual R (2018) Editorial overview: Relational values: What are they, and what's the fuss about? Curr Opin Environ Sust 35:A1-A7

Charles AT (1992) Fishery conflicts: a unified framework. Mar Pol 16:379-393

* Christensen V, Walters CJ (2004) Ecopath with Ecosim: methods, capabilities and limitations. Ecol Modell 172:109-139

* Clapham PJ (2015) Japan's whaling following the International Court of Justice ruling: brave new world - or business as usual? Mar Policy 51:238-241

* Constable AJ (2011) Lessons from CCAMLR on the implementation of the ecosystem approach to managing fisheries. Fish Fish 12:138-151

Cury PM, Boyd IL, Bonhommeau S, Anker-Nilssen T and others (2011) Global seabird response to forage fish depletion - one-third for the birds. Science 334:1703-1706

Dankel DJ, Aps R, Padda G, Rockmann C, Van der Sluijs JP, Wilson DC, Degnbol P (2012) Advice under uncertainty in the marine system. ICES J Mar Sci 69:3-7

DFO (Fisheries and Oceans Canada) (2002) Canada's oceans strategy: our oceans, our future. Cat. No. Fs23-116/2002E http://www.dfo-mpo.gc.ca/oceans/publications/cos-soc/ index-eng.html

DFO (2018) Stock assessment for Pacific herring (Clupea pallasii) in British Columbia in 2017 and forecast for 2018. DFO Can Sci Advis Sec Sci Advis Rep 2018/002

DFO (2019) Status of Pacifc herring (Clupea pallasii) in 2018 and forecast for 2019. DFO Can Sci Advis Sec Sci Rep 2019/001

* Díaz S, Demissew S, Carabias J, Joly C and others (2015) The IPBES conceptual framework - connecting nature and people. Curr Opin Environ Sustain 14:1-16

* Díaz S, Pascual U, Stenseke M, Martín-López B and others (2018) Assessing nature's contributions to people. Science 359(6373):270-272

* Dickey-Collas M, Nash RD, Brunel T, Van Damme CJ and others (2010) Lessons learned from stock collapse and recovery of North Sea herring: a review. ICES J Mar 
Sci 67:1875-1886

Dietz T (2013) Bringing values and deliberation to science communication. Proc Natl Acad Sci USA 110:14081-14087

Dietz T (2016) Environmental value. In: Brosch T, Sander D (eds) Handbook of value: perspectives from economics, neuroscience, philosophy, psychology, and sociology. Oxford University Press, Oxford, p 329-349

Engelhard GH, Peck MA, Rindorf A, Smout SC and others (2014) Forage fish, their fisheries, and their predators: who drives whom? ICES J Mar Sci 71:90-104

Essington TE, Munch SB (2014) Trade-offs between supportive and provisioning ecosystem services of forage species in marine food webs. Ecol Appl 24:1543-1557

Essington TE, Moriarty PE, Froehlich HE, Hodgson EE and others (2015) Fishing amplifies forage fish population collapses. Proc Natl Acad Sci USA 112:6648-6652

Failing L, Gregory R, Higgins P (2013) Science, uncertainty, and values in ecological restoration: a case study in structured decision-making and adaptive management. Restor Ecol 21:422-430

Fulton EA, Smith ADM, Smith DC, Johnson P (2014) An integrated approach is needed for ecosystem based fisheries management: insights from ecosystem-level management strategy evaluation. PLOS ONE 9:e84242

Funtowicz SO, Ravetz JR (1990) Uncertainty and quality in science for policy. Series A: Philosophy and methodology of the social sciences, Vol 15. Kluwer Academic Publishers, Dordrecht

Funtowicz SO, Ravetz JR (1993) Science for the post-normal age. Futures 25:739-755

Garcia SM, Cochrane KL (2005) Ecosystem approach to fisheries: a review of implementation guidelines. ICES J Mar Sci 62:311-318

Garcia SM, Zerbi A, Aliaume C, Do Chi T, Lasserre G (2003) The ecosystem approach to fisheries. Issues, terminology, principles, institutional foundations, implementation and outlook. FAO Fisheries Technical Paper 443. FAO, Rome

Gauvreau AM, Lepofsky D, Rutherford M, Reid M (2017) 'Everything revolves around the herring': the Heiltsukherring relationship through time. Ecol Soc 22:10

* Gluckman P (2014) The art of science advice to government. Nature 507:163-165

* Graham J, Haidt J, Koleva S, Motyl M, Iyer R, Wojcik SP, Ditto PH (2013) Moral foundations theory: the pragmatic validity of moral pluralism. Adv Exp Soc Psychol 47: $55-130$

Gregory R (2002) Incorporating value trade-offs into community-based environmental risk decisions. Environ Val 11:461-488

Gregory R, Failing L, Harstone M, Long G, McDaniels T, Ohlson D (2012) Structured decision making: a practical guide to environmental management choices. WileyBlackwell, Oxford

Grumbine RE (1994) What is ecosystem management? Conserv Biol 8:27-38

Haas AR, Edwards DN, Sumaila UR (2016) Corporate concentration and processor control: insights from the salmon and herring fisheries in British Columbia. Mar Policy 68: 83-90

* Hannesson R (2013) Strictly for the birds? On ecosystem services of forage fish. Mar Policy 38:109-115

Harris DC (2000) Territoriality, Aboriginal rights, and the Heiltsuk spawn-on-kelp fishery. Uni B C Law Rev 34: 195-238

Hauge KH (2011) Uncertainty and hyper-precision in fish- eries science and policy. Futures 43:173-181

*Heymans JJ, Coll M, Link JS, Mackinson S, Steenbeek J, Walters C, Christensen V (2016) Best practice in Ecopath with Ecosim food-web models for ecosystem-based management. Ecol Modell 331:173-184

* Hilborn R, Amoroso RO, Bogazzi E, Jensen OP, Parma AM, Szuwalski C, Walters CJ (2017) When does fishing forage species affect their predators? Fish Res 191:211-221

*Houle JE, Andersen KH, Farnsworth KD, Reid DG (2013) Emerging asymmetric interactions between forage and predator fisheries impose management trade-offs. J Fish Biol 83:890-904

Jennings S, Smith ADM, Fulton EA, Smith DC (2014) The ecosystem approach to fisheries: management at the dynamic interface between biodiversity conservation and sustainable use. Ann N Y Acad Sci 1322:48-60

Jentoft S, Chuenpagdee R (2009) Fisheries and coastal governance as a wicked problem. Mar Pol 33:553-560

Johnson DS, Lalancette A, Lam ME, Leite M, Pálsson SK (2019) The value of values for understanding transdisciplinary approaches to small-scale fisheries, In: Chuenpagdee R, Jentoft S (eds) Transdisciplinarity for smallscale fisheries governance: analysis and practice. MARE Publication Series, Vol 21. Springer International Publishing, Cham, p 35-54

Jones R, Rigg C, Lee L (2010). Haida marine planning: First Nations as a partner in marine conservation. Ecol Soc 15(1):12

Jones R, Rigg C, Pinkerton E (2017) Strategies for assertion of conservation and local management rights: a Haida Gwaii herring story. Mar Policy 80:154-167

Kahan D (2010) Fixing the communications failure. Nature 463:296-297

Kahan DM, Braman D, Gastil J, Slovic P, Mertz CK (2007) Culture and identity-protective cognition: explaining the white-male effect in risk perception. J Empir Leg Stud 4: 465-505

Kaiser M (2006) Practical ethics in search of a toolbox: ethics of science and technology at the crossroads. In: Gunning J, Søren H (eds) Ethics, law and society, Vol 2. Ashgate Publishing, Cardiff, p 35-44

Kaiser M (2012) Value isobars: the landscape and isobars of European values in relation to science and new technology. Final Report. EU Project 230557. European Commission Research and Innovation DG. www.value-isobars. eu/filestore/Finalreport1106312-1.pdf

Kaiser M (2016) Method in practical ethics: a call for a paradigm change. In: Olsson IAS, Araújo SM, Vieira MF (eds) Food futures ethics, science and culture. Wageningen Academic Publishers, Wageningen, p 142-147

Kaiser M, Millar K, Thorstensen E, Tomkins S (2007) Developing the ethical matrix as a decision support framework: GM fish as a case study. J Agric Environ Ethics 20:65-80

Kell LT, Levontin P, Davies CR, Harley S, Kolody DS, Maunder MN, Mosqueira I, Pilling GM, Sharma R (2016) The quantification and presentation of risk. In: Edwards CTT, Dankel DJ (eds) Management science in fisheries: an introduction to simulation-based methods. Routledge, New York, NY, p 348-374

King JR, McFarlane GA (2003) Marine fish life history strategies: applications to fishery management. Fish Manag Ecol 10:249-264

Kronlund AR, Forrest RE, Cleary JS, Grinnell MH (2018) The selection and role of limit reference points for Pacific herring (Clupea pallasii) in British Columbia, Canada. 
DFO Can Sci Advis Sec Res Doc 2018/009

Kumar R, Surma S, Pitcher TJ, Varkey D, Lam M, Ainsworth C, Pakhomov E (2016) An ecosystem model of the ocean around Haida Gwaii, Northern British Columbia: Ecopath, Ecosim and Ecospace. Uni B C Fish Cen Res Rep $24(2)$

Lam ME (2015) Opinion: Herring fishery needs integrated management plan. Vanc Sun 11.09.2015. www.vancouversun.com/technology/opinion+herring+fishery+needs +integrated+management+plan/11505147/story.html

Lam ME (2016a) Enhancing seafood ethics and sustainability (eSEAS): a values and ecosystem-based management approach. Marie Curie Individual Fellowship (MSCA-IFEF-ST) project 753937. European Commission

Lam ME (2016b) The ethics and sustainability of capture fisheries and aquaculture. J Agric Environ Ethics 29:35-65

Lam ME, Pauly D (2010) Who is right to fish? Evolving a social contract for ethical fisheries. Ecol Soc 15:16

Lam ME, Pitcher TJ (2012) The ethical dimensions of fisheries. Curr Opin Environ Sustain 4:364-373

Larkin PA (1996) Concepts and issues in marine ecosystem management. Rev Fish Biol Fish 6:139-164

Levin PS, Francis TB, Taylor NG (2016) Thirty-two essential questions for understanding the social-ecological system of forage fish: the case of Pacific herring. Ecosyst Health Sustain 2:e01213

Link JS (2002) What does ecosystem-based fisheries management mean? Fisheries (Bethesda) 27:18-21

Link JS (2010) Ecosystem-based fisheries management: confronting tradeoffs. Cambridge University Press, Cambridge

* Link JS, Pranovi F, Libralato S, Coll M, Christensen V, Solidoro C, Fulton EA (2015) Emergent properties delineate marine ecosystem perturbation and recovery. Trends Ecol Evol 30:649-661

Lockwood M, Davidson J, Curtis A, Stratford E, Griffith R (2010) Governance principles for natural resource management. Soc Nat Resour 23:986-1001

K Loring P, Hinzman MS (2018) 'They're all really important, but...': unpacking how people prioritize values for the marine environment in Haida Gwaii, British Columbia. Ecol Econ 152:367-377

Ludwig D, Hilborn R, Walters R (1993) Uncertainty, resource exploitation, and conservation: lessons from history. Science 260:17-36

Mallampalli VR, Mavrommati G, Thompson J, Duveneck M and others (2016) Methods for translating narrative scenarios into quantitative assessments of land use change. Environ Model Softw 82:7-20

* Marasco RJ, Goodman D, Grimes CB, Lawson PW, Punt AE, Quinn TJ II (2007) Ecosystem-based fisheries management: some practical suggestions. Can J Fish Aquat Sci 64:928-939

McClatchie S, Hendy IL, Thompson AR, Watson W (2017) Collapse and recovery of forage fish populations prior to commercial exploitation. Geophys Res Lett 44:1877-1885

McLeod K, Leslie H (eds) (2009) Ecosystem-based management for the oceans. Island Press, Washington, DC

Mepham B (2000) A framework for the ethical analysis of novel foods: the ethical matrix. J Agric Environ Ethics 12: 165-176

Möllmann C, Lindegren M, Blenckner T, Bergström L and others (2014) Implementing ecosystem-based fisheries management: from single-species to integrated ecosystem assessment and advice for Baltic Sea fish stocks.
ICES J Mar Sci 71:1187-1197

* Moran JR, Heintz RA, Straley JR, Vollenweider JJ (2018) Regional variation in the intensity of humpback whale predation on Pacific herring in the Gulf of Alaska. Deep Sea Res II 147:187-195

Moss ML (2016) The nutritional value of Pacific herring: an ancient cultural keystone species on the Northwest Coast of North America. J Archaeol Sci Rep 5:649-655

*Murphy J (2019) Facts, values, and the true cost of environmental harm. The Sealives Initiative. https://sealivesgallery. com/legacy-the-full-story/2019/2/16/facts-values-and-thetrue-cost-of-environmental-harm

${ }^{\prime}$ 'Leary BC, Smart JC, Neale FC, Hawkins JP, Newman S, Milman AC, Roberts CM (2011) Fisheries mismanagement. Mar Pollut Bull 62:2642-2648

Pakhomov EA, Hunt B, Trudel M, Pitcher TJ, Sergeenko N, Fladmark V, Schaub J (2017) Feeding dynamics of Pacific herring (Clupea pallasi) in the northeastern Pacific coast of Canada. In: Alheit J, Oozeki Y (eds) SPF 2017: Int Symp on Drivers of Dynamics of Small Pelagic Fish Resources, 2017, Mar 6-11, Victoria BC, Canada. Book of Abstracts. North Pacific Marine Science Organization (PICES), Sidney, p 109

* Pascual U, Balvanera P, Díaz S, Pataki G and others (2017) Valuing nature's contributions to people: the IPBES approach. Curr Opin Environ Sustain 26-27:7-16

Patrick WS, Link JS (2015) Myths that continue to impede progress in ecosystem-based fisheries management. Fisheries (Bethesda) 40:155-160

Perez MA (1994) Calorimetry measurements of energy value of some Alaskan fishes and squids. NOAA Tech Memo NMFS-AFSC-32

*Pikitch EK, Santora C, Babcock EA, Bakun A and others (2004) Ecosystem-based fishery management. Science 305:346-347

Pikitch E, Boersma PD, Boyd IL, Conover DO and others (2012) Little fish, big impact: managing a crucial link in ocean food webs. A report from the Lenfest Forage Fish Task Force. Lenfest Ocean Program, Washington, DC

* Pikitch EK, Konstantine JR, Essington TE, Santora C and others (2014) The global contribution of forage fish to marine fisheries and ecosystems. Fish Fish 15:43-64

*Pikitch EK, Boersma PD, Boyd IL, Conover DO and others (2018) The strong connection between forage fish and their predators: a response to Hilborn et al. (2017). Fish Res 198:220-223

Pinsky ML, Byler D (2015) Fishing, fast growth and climate variability increase the risk of collapse. Proc Biol Sci 282: 20151053

Pitcher TJ (1995) The impact of pelagic fish behaviour on fisheries. Sci Mar 59:295-306

Pitcher TJ (2001) Fish schooling: implications for pattern in the oceans and impacts on human fisheries. In: Steele $\mathrm{JH}$, Thorpe SA, Turekian KK (eds) Encyclopedia of ocean sciences. Academic Press, Cambridge, MA, p 975-987

* Pitcher TJ, Lam ME (2010) Fishful thinking: rhetoric, reality, and the sea before us. Ecol Soc 15(2):12

* Pitcher TJ, Kalikoski D, Short K, Varkey D, Pramod G (2009) An evaluation of progress in implementing ecosystembased management of fisheries in 33 countries. Mar Policy 33:223-232

Pitcher TJ, Lam ME, Kaiser M, White ASJ, Pakhomov E (2017) Hard of herring. In: Tortell P, Young M, Nemetz P (eds) Reflections of Canada: illuminating our opportunities and challenges at $150+$ years. Peter Wall Institute of 
Advanced Studies, Vancouver, BC, p 112-119

Plagányi ÉE (2007) Models for an ecosystem approach to fisheries. FAO Fish Tech Pap 477. FAO, Rome

*Plagányi ÉE, Essington TE (2014) When the SURFs up, forage fish are key. Fish Res 159:68-74

Punt AE, Butterworth DS, Moor CL, De Oliveira JA, Haddon M (2016) Management strategy evaluation: best practices. Fish Fish 17:303-334

PWIAS (Peter Wall Institute for Advanced Studies) (2016) Fishing for solutions in Haida Gwaii. Peter Wall Institute for Advanced Studies (PWIAS): The Wall Papers. April 26, 2016. https://pwias.ubc.ca/wall-papers/fishing-solutions-in-haida-gwaii

Rabinowicz W, Rønnow-Rasmussen T (2016) Value taxonomy. In: Brosch T, Sander D (eds) Handbook of value: perspectives from economics, neuroscience, philosophy, psychology, and sociology. Oxford University Press, Oxford, p 23-42

Raman S, Hobson-West P, Lam ME, Millar K (2018) Science matters and the public interest: the role of minority engagement. In: Nerlich B, Hartley S, Raman S, Smith A (eds) Science and the politics of openness: here be monsters. Manchester University Press, Manchester, p 230-250

Raskin P, Monks F, Ribeiro T, Vuuren D, Zurek M (2005) Global scenarios in historical perspective. In: Millennium ecosystem assessment, ecosystems and human wellbeing: a framework for assessment. Island Press, Washington, DC, p 35-43

Ravetz JR (1996) Scientific knowledge of social problems. Transaction Publishers, New Brunswick, NJ

Rittel HWJ, Webber MM (1973) Dilemmas in a general theory of planning. Policy Sciences 4:155-169

Rokeach M (1973) The nature of human values. Free Press, New York, NY

Ruckelshaus M, Klinger T, Knowlton N, DeMaster DP (2008) Marine ecosystem-based management in practice: scientific and governance challenges. Bioscience 58:53-63

Schwartz SH (1999) A theory of cultural values and some implications for work. Appl Psychol 48:23-47

Schwartz SH (2016) Basic individual values: sources and consequences. In: Brosch T, Sander D (eds) Handbook of value: perspectives from economics, neuroscience, philosophy, psychology, and sociology. Oxford University Press, Oxford, p 63-84

Scott J (2017) Identifying stakeholders' values and preferences for management of Pacific herring (Clupea pallasii) in British Columbia, Canada. MSc thesis. University of British Columbia, Vancouver, BC

Shelton AO, Samhouri JF, Stier AC, Levin PS (2014) Assessing trade-offs to inform ecosystem-based fisheries management of forage fish. Sci Rep 4:7110

Siple MC, Essington TE, Plagányi EE (2019) Forage fish fisheries management requires a tailored approach to balance trade-offs. Fish Fish 20:110-124

Sissenwine MP, Mace PM (2003) Governance for responsible fisheries: an ecosystem approach. In: Sinclair M, Valdimarsson G (eds) Responsible fisheries in the marine ecosystem. FAO, Rome, p 363-390

Skaret G, Pitcher TJ (2016) An Ecopath with Ecosim model of the Norwegian Sea and Barents Sea validated against time series of abundance. Prosjektrapport Havforskningsinstitutet Fisken og havet (IMR) 7-2016

Smith AD, Brown CJ, Bulman CM, Fulton EA and others

Editorial responsibility: Martin Quaas (Guest Editor),

Kiel, Germany
(2011) Impacts of fishing low-trophic level species on marine ecosystems. Science 333:1147-1150

Song AM, Chuenpagdee R (2015) Eliciting values and principles of fishery stakeholders in South Korea: a methodological exploration. Soc Nat Resour 28:1075-1091

Surma S, Pitcher TJ (2015) Predicting the effects of whale population recovery on Northeast Pacific food webs and fisheries: an ecosystem modelling approach. Fish Oceanogr 24:291-305

Surma S, Pitcher TJ, Perry RI, Kumar R (2017) A reassessment of carrying capacity estimates for Northeast Pacific herring stocks. In: Alheit J, Oozeki Y (eds) SPF 2017: Int Symp on Drivers of Dynamics of Small Pelagic Fish Resources, 2017, Mar 6-11, Victoria BC, Canada. Book of Abstracts. North Pacific Marine Science Organization (PICES), Sidney, p 127

* Surma S, Pakhomov EA, Pitcher TJ (2018a) Energy-based ecosystem modelling illuminates the ecological role of Northeast Pacific herring. Mar Ecol Prog Ser 588:147-161

* Surma S, Pitcher TJ, Kumar R, Varkey D, Pakhomov EA, Lam ME (2018b) Herring supports Northeast Pacific predators and fisheries: insights from ecosystem modelling and management strategy evaluation. PLOS ONE 13:e0196307

Surma S (2019) Pacific herring (Clupea pallasii) trophodynamics and fisheries in the Northeast Pacific Ocean. PhD thesis, University of British Columbia, Vancouver

Sydeman WJ, Thompson SA, Anker-Nilssen T, Arimitsu M and others (2017) Best practices for assessing forage fish fisheries-seabird resource competition. Fish Res 194: 209-221

* Thornton TF (2015) The ideology and practice of Pacific herring cultivation among the Tlingit and Haida. Human Ecol 43:213-223

Thornton TF, Moss ML, Butler VL, Herbert J, Funk F (2010) Local and traditional knowledge and the historical ecology of Pacific herring in Alaska. J Ecol Anthropol 14:81-88

*Uu-a-thluk (2018) Determining priorities for ?usmit (herring) in Nuu-chah-nulth Ha-ha-houlthee (chiefly territories) https://uuathluk.ca/determining-priorities-for-usmitherring-in-nuu-chah-nulth-ha-ha-houlthee-chieflyterritories/

$\operatorname{Vogl} J$ (2017) The science and art of the Haida's connection with herring. The Ubyssey. https://www.ubyssey.ca/ science/herring-people/

*Vollenweider JJ, Heintz RA, Schaufler L, Bradshaw R (2011) Seasonal cycles in whole-body proximate composition and energy content of forage fish vary with water depth. Mar Biol 158:413-427

*von der Porten S, Lepofsky D, McGregor M, Silver J (2016) Recommendations for marine herring policy change in Canada: aligning with indigenous legal and inherent rights. Mar Policy 74:68-76

Walters CJ, Christensen V, Martell SJ, Kitchell JF (2005) Possible ecosystem impacts of applying MSY policies from single-species assessment. ICES J Mar Sci 62:558-568

Walters C, Christensen V, Fulton B, Smith ADM, Hilborn R (2016) Predictions from simple predator-prey theory about impacts of harvesting forage fishes. Ecol Modell 337:272-280

Weber EP, Lach D, Steel BS (eds) (2017) New strategies for wicked problems: science and solutions in the 21st century. Oregon State University Press, Corvallis, OR

Submitted: October 17, 2017; Accepted: April 17, 2019

Proofs received from author(s): May 24, 2019 